\title{
De los discursos de identidad al activismo social: los movimientos sociales en la coyuntura de la nueva constitución cubana
}

From identity discourses to social activism: social movements at the juncture of the new Cuban constitution

Dos discursos de identidade ao ativismo social: movimentos sociais na conjuntura da nova constituição cubana

\section{Introducción}

El 2019 fue un año crucial para Cuba. En febrero, se aprobó una nueva Constitución, precedida por un intenso debate público acerca de sus contenidos, y el activismo ciudadano mostró un vigor y una visibilidad mayor que en décadas anteriores. A lo largo de todo el año las marchas por la protección animal y el orgullo gay y la presentación de varias peticiones de legislación, se combinaron con el uso masivo de redes y plataformas digitales como espacios de acción. Este artículo busca analizar estas acciones como innovaciones en los repertorios de algunos colectivos de la sociedad civil y explorar su relación con los cambios socioeconómicos, políticos y normativos más importantes ocurridos en el país en los últimos años.

Ya que el "renacer" de la sociedad civil cubana suele situarse en la década de los 90 del pasado siglo, esta tarea exige considerar trayectorias y procesos que han tenido lugar a lo largo de más de tres décadas. El punto de inicio coincide con un momento de cambios

Profesora Investigadora FLACSO, Sede México. Tlalpan, Ciudad de México, México. E-mail: <cbobes@flacso.edu.mx> 
profundos asociados a la crisis económica que dio lugar al "Periodo Especial”, cuando se evidenciaron los primeros signos de pluralización y heterogeneidad social junto a un (discreto) retraimiento del Estado y surgieron diversas asociaciones autónomas.

Desde esta diversidad se perfilaron dos ámbitos de autonomía social, uno más institucionalizado (organizaciones formales) y otro a partir de redes (informales) de solidaridad identitaria. El primero, se conforma por un amplio espectro de asociaciones de muy diferente grado de organización y aceptación, en uno de cuyos extremos se sitúa el conjunto de pequeñas organizaciones opositoras (grupos de derechos humanos, bibliotecas y prensa independientes), con agenda de cambio político y repertorio de denuncia, acciones no violentas y una experiencia de demanda legislativa ${ }^{2}$. Estas asociaciones no han sido nunca reconocidas por el Estado y su dinámica de interacción con él ha sido siempre de confrontación. Son ilegales y han sufrido persecuciones, represión, descalificaciones y exclusión. Aunque han tenido gran visibilidad externa, internamente el Estado ha sido exitoso en su neutralización y deslegitimación social, a partir de definirlos como "enemigos" y "agentes del gobierno de los Estados Unidos" y de la "mafia de Miami". Junto a ellas, se perfiló un variado conjunto de asociaciones con reconocimiento estatal que incluye, por una parte organizaciones laicas ${ }^{3}$, que aprovechan la institucionalización, infraestructura y financiamiento de sus iglesias para promocionar sus acciones (fundación de centros de pensamiento e investigación, trabajo filantrópico y asistencia social) y han mantenido vínculos de colaboración con instituciones estatales; y por la otra, movimientos barriales, que emprendieron, con mayor o menor éxito y continuidad, acciones encaminadas a

2 El Proyecto Varela; iniciativa llevada a cabo por el Movimiento Cristiano de Liberación en 1998, que, invocando varios artículos constitucionales, logró reunir más de las 10 mil firmas requeridas para solicitar cambios legales y constitucionales (derechos de libre expresión y asociación, amnistía para presos políticos, derechos a formar empresas privadas, nueva ley electoral), proponiendo que se sometieran a una consulta popular o referendo. La Asamblea Nacional del Poder Popular (ANPP), lo rechazó, considerándolo inconstitucional e improcedente, y reaccionó aprobando una reforma constitucional que declara al socialismo "irrevocable".

3 Entre ellas algunas ONG muy activas vinculadas tanto al protestantismo como el Centro Martin Luther King o el Centro Oscar Arnulfo Romero (OAR); como a la Iglesia Católica. 
la solución de problemas locales (proyectos y talleres de desarrollo comunitario, ambientalistas y de educación popular), estableciendo una forma de participación social y una dinámica colaborativa (no exenta de obstáculos y reticencias) autodefinida como complementaria al Estado.

El segundo ámbito de autonomía se configura a partir de redes informales de solidaridad, articuladas alrededor de innovaciones culturales y redefiniciones simbólicas de valores sociales referentes al género, la raza, la orientación sexual, etc., difundidos como discursos sociales alternativos que cuestionaban el discurso estatal de la unidad y la unanimidad desde identidades específicas. En este sentido, se inscriben en lo que se ha definido como movimientos identitarios, configurados a partir de redes informales y lazos solidarios no institucionalizados, cuyas demandas y acciones solo se comprenden en relación con la definición de sus identidades colectivas (MELUCCI, 2004; FOMINAYA, 2019). No obstante, a lo largo del tiempo, estos colectivos han venido evolucionando y enriqueciendo sus repertorios con diversas innovaciones (marchas, plantones, acciones performáticas, activismo digital y articulación de demandas de legislación y política pública) hasta llegar a constituir formas de activismo social más organizadas e independientes.

El objetivo de este artículo es hacer un balance de las trayectorias de los movimientos afrodescendiente, feminista, LGBTI y animalista ${ }^{4}$ para analizar tanto los modos que asume su relación con el Estado como los cambios de sus repertorios en los últimos años. Asimismo, ya que la introducción de innovaciones coincide con el proceso de discusión y aprobación de una nueva Constitución, interesa también explorar en torno a si y cómo este proceso, en sinergia con otros cambios significativos como la reforma económica y el acceso a herramientas digitales, se relaciona con la incorporación de nuevas estrategias por parte de los movimientos.

4 Es importante advertir que el trabajo no abarca la totalidad de organizaciones y actores de la sociedad civil cubana, sino que se focaliza en aquellos donde, a mi juicio, es más evidente el cambio de repertorio. 
Partimos del argumento de que tanto el nuevo escenario como los aprendizajes de los movimientos favorecen estos cambios. Para explicar cómo ocurre este proceso es conveniente asumir una perspectiva relacional que permita atender simultáneamente tanto a lo que hacen los actores (estatales y no estatales) como al contexto de interlocución. Este contexto, que constituye el ámbito de la agencia de los actores, establece un conjunto de incentivos y obstáculos dentro de los cuales se despliegan las elecciones, decisiones y capacidades subjetivas de los actores. Por ello, el análisis incluye una dimensión contextual que considera transformaciones asociadas al nuevo modelo de "actualización del socialismo" y cambios políticos y normativos, así como el examen de las diferentes estrategias y trayectorias de los movimientos a lo largo del tiempo.

En este sentido, se asume la importancia de combinar marcos analíticos de la literatura "clásica" de los movimientos sociales (nuevos movimientos sociales movilización de recursos, oportunidades políticas, marcos y repertorios de contención ${ }^{5}$ ) con reflexiones y conceptos provenientes de algunas contribuciones latinoamericanas recientes que abren nuevas rutas conceptuales para analizar, por una parte, la dinámica de construcción y modificación de los repertorios y por la otra, las relaciones entre los movimientos y el Estado, subrayando la conveniencia de atender no solo a lo contencioso sino también a las relaciones de colaboración que, en muchos casos, se producen entre ambos.

Siguiendo la propuesta de Rossi (2015) y dado que gran parte de las acciones de los movimientos que estudiamos no son ni contenciosas ni públicas, es positivo y realista complementar la definición de "repertorio de contención" (TILLY, 1978) con el concepto de "repertorio de estrategias" (conjunto históricamente determinado de opciones disponibles para la acción en la arena pública, semipública o privada) (ROSSI, 2015, p. 22). Por otra parte, ya que la renovación de los repertorios no puede verse solo como reacción a una "apertura de oportunidades políticas", es importante considerar

5 Las continuidades y divergencias entre las diferentes posiciones teóricas han sido discutidas ampliamente en la literatura (MCADAM; MCCARTHY; MAYER, 1996; FOWERAKER, 1995; DIANI, 2015). 
que los movimientos cuentan con un "stock de legados" (stock of legacies) que supone la acumulación de estrategias y acciones a partir de las cuales construyen sus repertorios desde la evaluación (correcta o no) de sus estrategias pasadas (o las de otros), lo que les permite optar por emularlas, readaptarlas o rechazarlas (ROSSI, 2015 , p. 22). Esta visión posibilita analizar innovaciones (en el corto y mediano plazo) que no dependen necesariamente de cambios de régimen o del Estado sino se relacionan con aprendizajes y enseñanzas, trasmisión intergeneracional, ensayo y error, influencia transnacional, etc. (ROSSI, 2015, p. 34).

Desde esta perspectiva, pueden analizarse no solo acciones contenciosas sino también la capacidad de los actores para desplegar una dinámica colaborativa con el Estado. La introducción al modelo analítico del concepto de "repertorio de interacción socio estatal" (ABERS; VON BÜLOW, 2011; ABERS; TATAGIBA, 2015; ABERS; SERAFIM; TATAGIBA, 2014) agrega la posibilidad de observar con mayor detalle el repertorio de estrategias no disruptivas y relaciones no contenciosas a través de las cuales los movimientos construyen vínculos de colaboración con el Estado para alcanzar sus objetivos, incluso trabajando dentro del aparato estatal (ABERS; VON BÜLOW, 2011, p. 78).

El concepto de "repertorio de interacción socio estatal" ha sido definido a partir de las experiencias de la relación de algunos movimientos sociales con gobiernos que han incorporado activistas a las instituciones encargadas de diseñar e implementar políticas públicas - en particular los gobiernos de Lula y Dilma en Brasil (ABERS; SERAFIM; TATAGIBA, 2014; ABERS; TATAGIBA, 2015) o los Kirchner en Argentina (ROSSI, 2015). Se trata de un conjunto de rutinas a través de las cuales se establece una relación no contenciosa con el fin de establecer procesos de negociación con el Estado. Tales rutinas van desde las protestas y acción directa hasta la participación institucionalizada (uso de canales oficiales con reglas aceptadas por ambas partes); la política de proximidad (a través de contactos personales de los activistas con los funcionarios, sin pasar por canales oficiales) y la ocupación de cargos en la burocracia por 
parte de activistas. Aunque en nuestro caso se observan algunas de estas rutinas y otras no, y predominan la colaboración y la negociación sobre la protesta, esto no solo no invalida la pertinencia del concepto, sino que, al introducir implícitamente un horizonte comparativo, subraya su valor para entender las peculiaridades que asume la interacción socio estatal en un contexto no democrático.

Finalmente, dado que muchas de las acciones de los movimientos involucran el uso de herramientas digitales, incorporamos también el concepto de Prácticas de Activismo Digital (PAD) (VON BÜLOW, 2018; VON BÜLOW; VILAÇA; ABELIN, 2018) para interpretar los diversos usos que los activistas dan a las nuevas tecnologías de la información en cada una de las etapas ${ }^{6}$. Asimismo, la introducción de la categoría de "subactivismo" aporta a la posibilidad de entender una forma de hacer política que no va más allá del nivel de la experiencia subjetiva y que se enraíza en el flujo de la vida cotidiana y no en las instituciones políticas ${ }^{7}$ (BAKARDJIEVA, 2009, p. 92).

La evidencia empírica para el análisis se ha construido a partir de la revisión de entrevistas de prensa, noticias, documentos, páginas web, blogs, perfiles de Facebook y otros contenidos de redes sociales. A partir de ellos, y estudios anteriores de la autora (BOBES, 2013, 2005) se elaboró un catálogo cronológico de las distintas acciones a partir del cual analizamos los repertorios en las diferentes etapas. De particular importancia resultaron los resúmenes anuales de la actividad de la sociedad civil cubana, que desde 2012 publica Inter Press Services de Cuba (IPS, 2020), así como entrevistas periodísticas a activistas publicadas por medios independientes ${ }^{8}$. El uso de fuentes noticiosas ya ha mostrado su validez y pertinencia para el análisis de las acciones de los movimientos sociales (ALMEIDA, 2020), asimismo en fechas recientes los sitios web y redes sociales de

\footnotetext{
6 Existen tres dimensiones de estas prácticas; presencia (tipos de plataformas usadas e intensidad de su uso), objetivos (que van desde los menos ambiciosos como proveer información, los debates interactivos on line hasta las convocatorias a protestas u otras formas de movilización) y audiencias (con quién buscan comunicarse) (VON BÜLOW, 2018).

7 Se trata de acciones y decisiones, a menudo individuales, de pequeña escala, pero cuyos marcos de referencia son políticos (BAKARDJIEVA, 2009, p. 92).

8 Entre ellos El Toque, Periodismo de Barrio, On Cuba, y YucaByte.
} 
los activistas han venido a incrementar la disponibilidad de información para la investigación académica (ALMEIDA, 2020, p. 78).

El texto se estructura en 3 apartados, el primero explicita el contexto socioeconómico, político y normativo y periodiza las trayectorias de los movimientos; el segundo expone sumariamente los casos empíricos, y el último discute la relación entre el proceso de aprobación de la Constitución de 2019 y las innovaciones en los repertorios de acción.

\section{De los discursos de identidad al activismo social}

\section{El Contexto}

El análisis de las trayectorias, experiencias y aprendizajes de los movimientos afro, feminista, LGBTI y animalista se enmarca en cambios en el contexto socioeconómico, político, cultural y normativo de Cuba en los últimos 30 años. Haciendo un esfuerzo por sintetizarlos, se podría hablar de una modificación del modelo socialista que comienza con las medidas de ajuste de los 90s, y culmina con la aprobación de una nueva Constitución. Todos estos cambios tuvieron consecuencias sobre la sociedad y sus relaciones con el Estado.

Las primeras reformas comprendieron la apertura al exterior de la economía (inversiones mixtas y de capital extranjero) y el trabajo por cuenta propia; la legalización de la tenencia de divisas y la descentralización y racionalización del aparato estatal, lo que estimuló una incipiente diversificación de la estructura social y cierto retraimiento del Estado que abrió paso a una mayor autonomía social ${ }^{9}$. A la vez, la reforma constitucional de 1992 legitimó algunos mecanismos de mercado, amplió (mínimamente) la inclusión en

9 Antes, el control del Estado sobre empleos, ingresos, distribución y consumo, así como sobre la educación y los medios de comunicación, había configurado una sociedad homogénea, cuya participación se limitaba a las organizaciones de masas, con objetivos y formas movilizativas fijados desde arriba. 
la comunidad política ${ }^{10}$ y la promulgación de una ley de asociaciones posibilitó establecer organizaciones civiles. No obstante, persistieron los obstáculos al asociacionismo independiente; como condicionar los derechos de asociación, manifestación y reunión a su ejercicio dentro de las organizaciones de masas (ANPP, 1992, Art 53) y las restricciones presentes en la Ley de Asociaciones y su reglamento, cuyos requisitos incluyen la necesidad de autorización del Ministerio de Justicia, y condicionan el reconocimiento y registro, a que no exista ninguna otra asociación con idéntica o similar denominación, o con iguales objetivos; asimismo, confiere potestad a las autoridades para disolver aquellas que incumplan estos principios, violen leyes, o sus actividades "se tornen lesivas al interés social" (ANPP, 1985, s. p.).

Durante los últimos 30 años, las reformas han experimentado diversos ritmos, dinamismos y vaivenes relacionados con las disímiles coyunturas, pero desde 2006 (y particularmente después de 2011) se han profundizado. Con el traspaso de los cargos de Fidel Castro a su hermano Raúl, inició un proceso paulatino de renovación del liderazgo que ha estado acompañado de reestructuraciones político-administrativas y de la proclamación de una nueva Constitución en 2019. La política económica experimentó un viraje con la introducción de un conjunto de medidas que abarcaron la eliminación de prohibiciones, la entrada de mecanismos de mercado, ampliación del trabajo por cuenta propia, cambios en los sistemas de seguridad social y de pensiones, la distribución de la tierra y otras medidas de corte estructural (MESA-LAGO, 2012). Como resultado de estas disposiciones se produjeron modificaciones en el mundo del trabajo, aumentaron la desigualdad ${ }^{11}$ (de ingresos, consumos, espacial y territorial, de acceso a servicios y prestigio

10 La reforma constitucional del 92 redefine el "Estado de obreros y campesinos" (ANPP, 1992) como Estado socialista de trabajadores y elimina el principio de ateísmo; flexibiliza la propiedad estatal, reconoce las empresas mixtas y el trabajo por cuenta propia. Estas discretas ampliaciones favorecieron la diversidad social (BOBES, 2015).

11 Aparecen nuevos sujetos económicos como los trabajadores por cuenta propia, pequeños empresarios privados, receptores de remesas, etc. El aumento de la desigualdad puede apreciarse en la variación del coeficiente de GINI (de 0.22 en 1986 a 0.402 en 2000) (MESA-LAGO, 2005). Sobre el tema de la desigualdad, ver (ESPINA, 2010; MESA-LAGO, 2012; BOBES, 2015). 
social), la pobreza y la informalidad (con sobrerrepresentación de mujeres y afrodescendientes); e inició un proceso de reconfiguración de la estructura social ${ }^{12}$.

Durante estas décadas ha ido creciendo paulatinamente la conectividad y el acceso a internet. Si en los 90 s apenas un pequeño grupo de personas tenía acceso a correo electrónico y a Internet a través de unos pocos canales oficiales y muy controlados por el Estado, en 2007 la autorización de la compra de computadoras y teléfonos celulares a particulares elevó las posibilidades de conexión. En 2013 abren las primeras salas de navegación para uso público, en 2014 inicia la comercialización del servicio de correo Nauta para usuarios privados; en 2015 se abren los primeros sitios púbicos de conexión wifi y a finales de 2016 inicia el servicio Nauta Hogar de suscripción a Internet en los domicilios; hasta que finalmente en 2018 se instauró el servicio de conexión por datos móviles ${ }^{13}$.

Este escenario constituye el contexto para analizar los eventos y etapas de los movimientos, identificar y caracterizar sus repertorios de estrategias y las formas de interacción que desarrollan.

\section{Los movimientos}

Los movimientos que estudiamos aquí tienen varios rasgos comunes. El primero, su origen en identidades colectivas no formalizadas en organizaciones. El segundo, que comparten un mismo posicionamiento respecto al abanico de asociaciones de la sociedad civil y la historia de su relación con el Estado. Se trata de grupos que no cuestionan el sistema político, se esfuerzan por mantenerse en los cauces de la legalidad y distinguirse y tomar distancia de las organizaciones disidentes; lo que consiguen a través de enfatizar objetivos no políticos sino dirigidos a cambios de valores culturales y prácticas sociales derivadas de ellos. No obstante, como los temas

\footnotetext{
12 Algunos autores (MESA-LAGO, 2012, 2005; ZABALA ARGÜELLES, 2008; ESPINA, 2010) hablan de pobreza racializada y feminizada. Sobre el proceso de reconfiguración de la estructura social, ver Bobes (2015).

13 El incremento de usuarios conectados ha ido de $0.5 \%$ en 2000; a 12.9\% en 2008; 30\% en 2014; 32.4\% en 2016; hasta llegar en 2019 al 56\% (con un 40\% de la población conectada a través de sus celulares) (ALONSO, 2019) y a un 63\% en 2020 (EFE, 2020).
} 
de género, orientación sexual y raza, también son reafirmados y retomados por algunas organizaciones disidentes (a quienes no consideran aliados ni semejantes), el deslinde respecto a esas organizaciones también implica la elección de estrategias no disruptivas y subordinar sus dinámicas contenciosas a la colaboración con el Estado. Por ello, su repertorio de estrategias ha estado moldeado por un stock de legados del cual han aprendido a delimitar lo permitido, lo prohibido y lo posible; evitando formas de acción ${ }^{14}$ ante las cuales el Estado ha respondido con rechazo, represión y demonización y que han quedado identificadas en el imaginario social y en el discurso oficial con lo subversivo, antisocialista y proimperialista.

El último rasgo común, es el paso en sus trayectorias por tres fases diferentes: un primer momento de conformación de identidades (con algunos intentos fallidos de formar organizaciones); una segunda etapa en la que desarrollan una dinámica de colaboración con las instituciones estatales y con ONGs reconocidas; y la etapa actual de activismo más independiente.

La distinción entre unas fases y otras se relaciona tanto con elementos del contexto como con aspectos de la agencia. En la etapa fundacional predominan elaboraciones discursivas que cuestionan la narrativa estatal de que, con la revolución y la eliminación de la explotación, automáticamente se había logrado la igualdad y equidad para todos los grupos (mujeres, afrodescendientes, etc.). Desde esta narrativa, que supone la unidad del pueblo como consustancial y necesaria al sistema y cualquier diferencia puede ser interpretada como disenso político, el Estado cubano impone restricciones a la acción colectiva autónoma y es reacio a la formación de asociaciones independientes, aunque se muestra capaz de tolerar los debates identitarios que se producen en espacios culturales y académicos.

En esta etapa se producen algunos intentos por constituir organizaciones, animadas tanto por la diversificación social y la fundación de diversas ONGs, como por la promulgación de la ley de

14 Como peticiones de reformas democráticas, protestas en espacios públicos, iniciativa legislativa, huelgas de hambre, denuncias ante organismos de derechos humanos. 
asociaciones. Sin embargo, el Estado no las reconoce, les niega el registro y "desactiva" las que alcanzaron a constituirse. A diferencia de las de oposición, que persisten en organizarse al margen el Estado y operar en la ilegalidad, los colectivos basados en identidades optan por mantenerse como redes informales.

Para estos actores, los espacios de discusión son, en esta etapa, el meollo de la acción colectiva ya que constituyen la base para la reinterpretación y elaboración discursiva de su autodefinición. Estas reelaboraciones y los debates desarrollados a su alrededor configuran una forma de subactivismo (BAKARDJIEVA, 2009; SÁNCHEZ-DUARTE; FERNÁNDEZ ROMERO, 2017; HOLZER; SØRENSEN, 2003) que permite comprometerse e identificarse con ciertos temas y causas a través de acciones de expresión subjetiva, tanto en espacios físicos como en la web. Aunque los discursos identitarios contenían denuncias de discriminaciones o exclusiones y demandas de reconocimiento, mantenerlos al margen de la política elevaba la posibilidad de ser tolerado o escuchado por las instituciones. Este subactivismo establece las bases a partir de las cuales se constituyeron y fortalecieron identidades, se difundieron sus discursos, se construyeron solidaridades y se crearon los núcleos básicos de activistas que articularon las agendas posteriores.

Con la entrada del Internet (1996) muchas de las acciones transcurrieron de manera virtual, configurándose las primeras Prácticas de Activismo Digital (PAD) (VON BÜLOW, 2018) (VON BÜLOW; VILAÇA; ABELIN, 2018). Estas primeras PAD se caracterizaron por ser acción colectiva digital que transcurre en la red (distinta de la que usa la red como soporte para convocar, organizar o movilizar a acciones no digitales) (SÁNCHEZ-DUARTE; FERNÁNDEZ ROMERO, 2017). Respecto a los tipos de plataformas, involucró mayormente el correo electrónico, pero también se crearon boletines digitales, blogs y sitios web que usaban videos y audios para difundir sus acciones y las de otros actores independientes. Aunque sus objetivos se limitaban a la diseminación de información y crear foros para el debate sobre los temas identitarios, las PAD horizontalizaron la comunicación; fueron vehículos para mensajes 
alternativos a los estatales; consiguieron audiencias para eventos no publicitados por el Estado; contribuyeron a sortear el control estatal (con bajos costos) y, en tanto facilitaron establecer relaciones con académicos y activistas de otros países, abonaron a la introducción de otros lenguajes y nuevas perspectivas de autodefinición. A pesar de que el Estado también intentó controlar el acceso y regular el uso de Internet ${ }^{15}$ (casi exclusivamente a través de centros estatales), por su intermedio los debates de la sociedad civil, antes "ocultos", se tornaron visibles (HOFFMANN, 2011), lo que abonó a la diversificación de una esfera pública que hasta entonces había monopolizado el Estado.

La segunda etapa de los movimientos se caracteriza por el despliegue de una estrategia de colaboración o alianza con el Estado y/o con ONGs que cuentan con reconocimiento estatal. Al igual que en otros países de América Latina (Brasil, Argentina), también en Cuba los movimientos intentan utilizar al Estado como plataforma para darle visibilidad y eficacia a sus demandas (ABERS; VON BÜLOW, 2011, p. 66). El repertorio incluye la promoción de campañas conjuntas, la creación de espacios e introducción de temas de discusión en organismos estatales, la participación de algunos activistas en otras ONGs y un caso de activismo institucional. Aunque este repertorio se asemeja al descrito por Abers y von Bülow (2011) es importante discutir algunas diferencias.

Para analizar esta dinámica de colaboración en el caso cubano hay que partir de las características del sistema político y el Estado con el que se relacionan los movimientos. En un sistema de partido único, sin competencia electoral, con derechos de asociación y manifestación limitados, el Estado posee una altísima capacidad de control sobre las esferas política, económica, cultural y simbólica; controla los medios de comunicación y el espacio público, tutela y restringe las posibilidades de organización de la sociedad civil, recela de las autonomías sociales y reprime las manifestaciones de las organizaciones disidentes; no solo no existen canales

15 El Decreto Ley 209 establecía el uso regulado y selectivo de Internet, priorizando el acceso a instituciones importantes para el desarrollo del país y en función de los intereses nacionales. 
independientes de financiamiento sino que el Estado demoniza los de agencias internacionales (identificándolos con la agenda de subversión del gobierno de los Estados Unidos y los grupos anticastristas del exilio). Se trata de un Estado altamente centralizado donde las decisiones se toman en el gobierno central ${ }^{16}$ y que, a diferencia de otros gobiernos de la región, no ha creado nuevos mecanismos de democracia participativa (consejos consultivos, presupuestos participativos, etc.) ni instancias formales de acceso de la sociedad civil a las instituciones gubernamentales.

En este escenario los activistas se ven motivados a interactuar no contenciosamente con el Estado. Ante las experiencias de desarticulación de organizaciones en los 90s y la represión, neutralización y deslegitimación de las organizaciones opositoras (ambas presentes en su stock de legados), la colaboración parece ser una opción razonable, por lo que puede interpretarse como una estrategia exitosa de los movimientos para adaptarse a este entorno y sortear los desafíos que les impone. Esta cooperación les ofrece además algunos beneficios: obtienen espacios para hacerse escuchar y promover sus demandas; consiguen difundir y legitimar sus discursos y agendas en el espacio público; aprovechan los recursos estatales (y los de las ONGs reconocidas) y ha permitido a algunos activistas tener presencia en organismos que deciden políticas públicas ${ }^{17}$.

Por su parte el Estado - que, aunque es fuerte, tiene pocos canales para asimilar y procesar identidades específicas y demandas de grupos particulares (ya que subordina los intereses particulares a la unidad nacional y al proyecto socialista)-, con esta colaboración abre un medio para ello. Otras ganancias para el Estado son: que consigue un modo (suave) de control, ya que, sin perder su poder, delimita (dirige y lidera) aquellas acciones que puede manejar y permitir, y evita las que realmente lo cuestionan y amenazan; marca una diferencia entre movimientos leales y demandas legítimas $v s$. movimientos contra el sistema y demandas inaceptables; incentiva

16 Lo que descarta las negociaciones de los movimientos con instancias locales de gobierno (como ocurre en otros casos latinoamericanos).

17 Es el caso del movimiento LGBTI en el Centro Nacional de Educación Sexual (CENESEX). 
las acciones no contenciosas y desincentiva las contenciosas; y obtiene conformidad y gratitud de los movimientos. Por último, a través de la organización o auspicio de sus acciones, tiene una vía para cumplir compromisos derivados de acuerdos y tratados internacionales donde puede incluir a los activistas y mostrar al mundo una voluntad de colaboración con la sociedad civil.

No obstante, no todo es "ganar/ganar", más bien el resultado de esta estrategia es ambivalente. Mucho se ha discutido acerca de si estas dinámicas colaborativas debilitan o fortalecen los movimientos, subrayando los riesgos de desmovilización y burocratización que entrañan para el activismo independiente (ABERS; TATAGIBA, 2015; ROSSI, 2015). En nuestro caso, esta estrategia ha fortalecido a los activistas (a contrapelo de los intereses del Estado), pero también los ha limitado y ha producido más cooptación que influencia, ya que al final las decisiones las toman las instituciones y la subordinación al Estado ha neutralizado o bajado la intensidad de las demandas; lo que parece ser una de las razones para la emergencia de un activismo más independiente.

Este nuevo activismo marca la configuración de una tercera etapa, caracterizada por las innovaciones en los repertorios de estrategias y la redefinición de demandas. Este cambio, favorecido por los aprendizajes y la evaluación de la dinámica colaborativa, puede interpretarse también relacionado a dos importantes acontecimientos: la nueva Constitución y el acceso a datos móviles. Las modificaciones de los últimos años involucran tanto a los repertorios como a la relación con el Estado; se introducen performances artísticos, marchas y plantones; algunas reivindicaciones empiezan a apuntar a problemas derivados de la nueva situación económica ${ }^{18}$; los discursos de identidad y los reclamos de reconocimiento comienzan a reinterpretarse en relación con determinadas acciones $\mathrm{u}$ omisiones del poder, y las demandas a articularse en un lenguaje de derechos. Con lo cual el activismo (sin abandonar la colaboración) se hace cada vez más independiente.

18 En particular la sobrerrepresentación de afrodescendientes y mujeres en los estratos más pobres. 
Todo ello se amplifica y visibiliza por el creciente uso de redes sociales ${ }^{19}$ y plataformas digitales y la introducción de nuevas PAD. Si antes el Internet funcionó principalmente como espacio de deliberación colectiva, constitución identitaria y medio para el subactivismo, ahora apunta a acciones más proactivas como su utilización en la difusión de campañas, mecanismo de coordinación y movilización, y organización de protestas.

Las ventajas del uso de las redes por parte de los movimientos, en el sentido de facilitar la coordinación y movilización, han sido extensamente estudiadas tanto en contextos democráticos (CHADWICK 2007; EARL, 2019; EARL; KIMPORT, 2011; VON BÜLOW, 2018) como no democráticos (HOFFMAN, 2011; CHEN; MOSS, 2019). En el caso de los activistas cubanos el acceso a redes como Facebook, Twitter, Instagram, WhatsApp y Telegram les ha permitido incrementar cualitativa y cualitativamente el uso de Internet, no solo para promover acciones en la red sino también para la movilización off line. Ya que los datos móviles son más dinámicos que las listas de correo electrónico permiten mayor inmediatez, alcanzar nuevos públicos, reclutar más potenciales adeptos, y lograr más apoyos transnacionales; asimismo el uso de plataformas digitales facilita la divulgación de cartas abiertas y peticiones y multiplica las posibilidades de recogida de firmas. En un contexto donde los activistas no pueden siquiera formalizar asociaciones para allegarse recursos materiales y chocan con diversas trabas por parte del Estado, el activismo digital constituye una alternativa a las acciones en espacios físicos y los contactos virtuales pueden complementar (o sustituir) las relaciones cara a cara. Este medio además les permite aprovechar las habilidades y competencias de sus recursos humanos ${ }^{20} \mathrm{y}$ abrir fisuras a los controles estatales.

19 En 2019, del 56\% de la población conectada a internet, prácticamente todos (6.47 millones) estaban vinculados a alguna de las redes sociales, la mayoría de ellos a través de sus teléfonos celulares (ALONSO, 2019).

20 Análisis sobre otros países y regiones han descrito situaciones similares. Por ejemplo (TARROW, 2011; BAKARDJIEVA, 2009; CHU, 2019) 
Las trayectorias de los movimientos afro, feminista, LGBTI y animalista, que se resumen ${ }^{21}$ a continuación ofrecen evidencia empírica sobre la incorporación de diferentes de estrategias en las tres etapas, así como las innovaciones introducidas en sus repertorios en el contexto de reemplazo constitucional.

\section{Los casos empíricos}

\section{El movimiento afrodescendiente.}

$\mathrm{Su}$ agenda antirracista se articula alrededor de un debate social acerca de la pervivencia de racismo y discriminación racial tanto en la sociedad como en las instituciones estatales. Tienen como antecedente el rechazo del Estado a algunos proyectos culturales de reafirmación de lo negro en la cultura cubana emprendidos por diversos intelectuales en los 60s y los 70s del siglo pasado. A partir de la reunión de grupos de intelectuales, artistas, académicos, religiosos y promotores culturales en diversos espacios, se fue configurando un "movimiento cultural afrocubano" (DE LA FUENTE, 2012) cuyo repertorio apunta al subactivismo a través del desarrollo de un trabajo de reflexión y producción de discursos que exaltan la negritud y reafirman la identidad negra. Aunque en sus momentos iniciales casi todas sus acciones son discursivas e intelectuales, también se fundaron asociaciones como la Cofradía de la Negritud (1998).

En este primer momento se denuncian prácticas discriminatorias y racismo en diferentes ámbitos (trabajo, medios de comunicación y vida cotidiana), realizan foros, actividades artísticas (hip hop) y proyectos comunitarios. Su discurso de reafirmación identitaria se difundió principalmente en reuniones en espacios físicos y a través de boletines por correo electrónico, blogs y páginas web ${ }^{22}$. Este subactivismo, jugó un rol relevante en la formación y reafirmación de la identidad afro, la cohesión de una red solidaria alrededor del

21 Por razones de extensión de este texto, lo que se presenta es una síntesis de acciones y organizaciones que no las abarca en su totalidad.

22 Por ejemplo, desde finales de los 90s existían el boletín Desde la Ceiba, de la Cofradía de la Negritud, el blog AfroCuba (1993) y el portal AfroCubaWeb (que inició en 1992 como lista de correo y desde 1997 existe como portal) (AFROCUBAWEB, s. d.; KING, 2019). 
tópico y el establecimiento de contactos y relaciones con académicos, y activistas de otros países que aportaron a los nacionales sus experiencias, estrategias y modos de presentar el tema.

A lo largo de las últimas décadas estas redes y colectivos van ganando complejidad y visibilidad y radicalizando sus posturas. Sin abandonar el subactivismo y las PAD en foros virtuales ${ }^{23}$, a partir del 2010 se aprecia un mayor activismo social con la proliferación de nuevas asociaciones como la Red Barrial Afrodescendiente (2012), el Grupo Afrocubanas (2016), y la alianza Afrocubana (2017), y una diversificación de los repertorios y estrategias (acciones de educación y concientización para el empoderamiento de comunidades afro a nivel barrial o local, envío de cartas con reclamos o quejas a diferentes instituciones ${ }^{24}$ ). Asimismo, se produce la intersección del tema racial con asuntos de género y/o diversidad sexual y la colaboración con esos movimientos. La creación del colectivo de juristas Alianza Unidad Racial (2011) introduce una agenda de acompañamiento legal a personas víctimas de discriminación, y en 2017 logran presentar por primera vez una denuncia penal por discriminación racial. A su vez, los cambios de repertorio se acompañan del ingreso al discurso identitario de una valoración acerca de cómo los cambios económicos impactan negativamente al tema racial (como evidencia este testimonio):

Conscientes de que las profundas desigualdades sociales que generaron los cambios económicos que se llevaron a efecto como medidas para la palear la crisis económica que afectaba el país, impactaban con más fuerza a la población más desposeída, entre las que se encontraba en muchas de las comunidades cubanas, la afro descendiente, hizo que las integrantes del Grupo Afrocubanas nos trazáramos como

23 De hecho, en la segunda etapa proliferan nuevos blogs y foros digitales como AfroModernidades, Negra Cubana Tenía que Ser, y otros. Muchos de ellos, en los últimos tres años se han replicado en Facebook y Twitter.

24 Aunque La Cofradía comienza a hacer esto en 1999 (carta al Ministro de Educación), la práctica parece hacerse más frecuente a partir de 2006 con envíos al presidente de la ANPP y a medios de comunicación. 
nueva meta incorporarnos al camino del activismo social, independientemente del compromiso y el sacrificio que requería. En tal sentido, acompañamos a la Red Barrial Afro Descendiente a través de un plan temático de capacitación sobre la problemática racial en Cuba, encaminado al empoderamiento y producción de saberes de todas y todos los integrantes de ese grupo comunitario. (RUBIERA, 2018, s. p.).

Todas estas organizaciones y colectivos comparten identidad, tema y objetivo, pero marcan una diferencia con las organizaciones disidentes (como la Alianza Unidad Racial fundada en 2011). Como indica la crónica de los debates del encuentro de activistas afrocubanos en la Universidad de Harvard en 2017:

Notablemente ausentes del evento estuvieron algunas organizaciones disidentes que trabajan el tema racial. De la Fuente explicó que su no inclusión fue una decisión consensuada y que se basó en el hecho de que estos grupos no consideran la lucha contra la discriminación racial como su principal objetivo. (GÁMEZ, 2017, s. p.).

La relación con el Estado es compleja. Por una parte, éste ha tendido a negar o minimizar el problema de la discriminación y el racismo y a subrayar los avances obtenidos vía sus políticas de redistribución y justicia social; mientras que ve en la reafirmación de la identidad afro un elemento divisivo (perjudicial) a la "unidad revolucionaria". Por la otra, ha accedido a atender la demanda de incorporar el tema en instituciones culturales, investigativas y en los medios, lo que ha abonado a una dinámica colaborativa (no exenta de críticas y reclamos por parte de los activistas). Ésta se muestra en la promoción y auspicio estatal de coloquios, publicaciones y debates públicos y en la fundación de proyectos dentro de varias instituciones oficiales, así como la adscripción o articulación de algunas asociaciones con organismos del Estado (Color Cubano/ Comisión Aponte en la Unión de Escritores y Artistas de Cuba 
UNEAC, la Red de Mujeres Afro Latinoamericanas, Afrocaribeñas y de la Diáspora en Cuba, articulada a la Federación de Mujeres Cubanas FMC).

Esta cooperación se ve favorecida por la dimensión transnacional ya que el Estado consiente y/o auspicia ciertas acciones en el marco de convenios y compromisos internacionales. Ejemplos de ello son tanto la fundación de Articulación Regional Afrodescendiente de América Latina y el Caribe, Capítulo Cubano ${ }^{25}$ ARACC (vinculada al Ministerio de Cultura), como la organización en 2014 de la I Jornada Cubana contra la Discriminación Racial, que tuvieron lugar durante el Decenio de los Afrodescendientes declarado por la ONU. A la vez también en esta dimensión afloran las dificultades de la dinámica colaborativa ${ }^{26}$ lo que se evidencia por ejemplo en la presentación de las objeciones de los activistas al Informe sobre la problemática racial presentado por el gobierno de Cuba a la ONU en 2018 (Examen Periódico Universal del Consejo de Derechos Humanos), donde denuncian la tendencia estatal a negar la existencia de racismo y discriminación racial, su falta de voluntad para presentar estadísticas por raza y reclaman acciones y políticas al respecto (COMISIÓN JOSÉ ANTONIO APONTE, 2018).

Aunque el Estado siempre se ha mostrado remiso y suspicaz con el movimiento, recientemente (2020) ha creado un Programa Nacional contra la Discriminación Racial, coordinado por una comisión dirigida por el presidente de la República e integrada por 18 entidades estatales, 12 investigativas y 18 organizaciones de la sociedad civil, lo que se ha interpretado como una respuesta

25 Que también insiste en desmarcarse de la oposición "ARAAC is a concept endorsed by a number of activists across Latin America [...] ARAAC's Cuba chapter [...] includes veteran investigators on race \& identity [...] It is not a dissident organization" (AFROCUBAWEB, s. d.), mi subrayado.

26 La Jornada Cubana contra la Discriminación Racial, auspiciada por el Estado, no tuvo continuidad. Según testimonio de activistas: "[...] la breve vida del capítulo cubano de la Articulación Regional Afrodescendiente (ARAC) -una organización que nació oficialmente en mayo del 2013, según una versión por la presión desde abajo de líderes afrodescendientes de Cuba y América Latina, y según otra, como una idea del Estado- llama la atención, por ser esta una organización que pretendía unificar el movimiento y'transitar de grupo de interés a grupo de presión' para combatir la discriminación racial [... La ruptura que sobrevino después señaló la investigadora Gisela Arandia 'fue de tipo institucional"' (GÁMEZ, 2017, s. p.). 
favorable a sus demandas, y reclamos ${ }^{27}$ y parece apuntar a un cambio en la relación del Estado con el activismo afro, ya que al incorporarlos a este programa de gobierno tácitamente los reconoce y legitima en su autonomía.

\section{Feminismo}

También estos colectivos surgen en los 90s vinculados a debates académicos y culturales que demandan la incorporación de la perspectiva de género en la cultura, los medios y la educación. En 1993 se funda la ONG MAGIN por parte de un conjunto de comunicadoras y académicas que buscaban incluir la perspectiva y los debates de género tanto al análisis social como a la opinión pública. Después de tres años de muchas presiones, la organización fue desactivada por el Estado. Según testimonios de sus fundadoras, cuando en 1996 solicitaron reconocimiento legal les respondieron que debían disolverse, porque ya existía una organización femenina (la FMC) y porque podrían ser utilizadas por grupos y fuerzas subversivas desde fuera o dentro del país (PIKARA MAGAZINE, 2018). Esta desactivación y los motivos aducidos sentaron un precedente para las activistas que llegaron después (e incentivó la colaboración con el Estado); desde entonces, el movimiento fue creciendo a través del trabajo de académicas, artistas e intelectuales que continuaron presionando y promoviendo la incorporación de la perspectiva de género en investigaciones, docencia y la cultura, pero eligieron evitar la creación de asociaciones formales. Al respecto, es ilustrador el análisis de una académica/activista:

Cuando hablo de vulnerabilidad hablo de los dos mayores peligros que puede enfrentar el activismo feminista en Cuba. Por un lado, está el ejemplo de MAGIN para demostrarnos cómo cuando un colectivo gana visibilidad y capacidad de interlocución pública los poderes establecidos le niegan la

27 Según se afirmó al momento de su creación "llegó un momento en que las conversaciones, tanto del Gobierno como de la sociedad civil, demandaban un salto de calidad y ser tratadas desde el trabajo de la propia dirección del país" ( FUENTES PUEBLA; GARCÍA ACOSTA, 2020, s. p.). 
sal y el agua, pues conciben el espacio público como dominio exclusivo suyo - en lugar de incorporarse a su vez al debate público y trabajar conjuntamente con el colectivo que lo está interpelando o buscando su cooperación- y borran de él (o al menos lo intentan) la presencia de lo otro, que se vive como una agresión a su autoridad. (CAPOTE, 2017, s. p.).

Ante la imposibilidad de formar organizaciones propias con reconocimiento legal, el movimiento estableció colaboración con instituciones estatales (la UNEAC, el Ministerio de Cultura, la Casa de las Américas, las Cátedras de Estudios de la Mujer, la FMC y el CENESEX, entre otros). A esta estrategia se sumó la de formar alianzas con ONGs reconocidas, integrándose e impulsando su agenda en diversos proyectos y campañas dentro de las que incluyen el tema en sus programas ${ }^{28}$, como el centro OAR (que ha coordinado las campañas Evoluciona, Únete, Eres más, Van de la Mano y ha implementado talleres barriales de empoderamiento femenino y liderazgos) y la Red Iberoamericana de Masculinidades. También se han producido alianzas con otros colectivos del movimiento afro ${ }^{29}$ y LGBTI.

A diferencia del movimiento afro, en el caso del feminismo, en la colaboración con el Estado ha coadyuvado la coincidencia de las agendas del movimiento con objetivos y políticas estatales en tópicos referentes a la igualdad, la incorporación laboral de la mujer, salud reproductiva, etc. Así como también por la dimensión transnacional; siendo el país signatario de los tratados y acuerdos sobre la mujer se han implementado diversos programas, como el Grupo de Trabajo para la Atención a la Violencia Intrafamiliar, las cátedras de la mujer en universidades, programas de educación no sexista y el auspicio de jornadas nacionales por la no violencia, en la que

28 Así explicita una activista estas estrategias: "Intentar mantener un espacio de independencia; establecer alianzas puntuales de trabajo con las instituciones $u$ organizaciones existentes para temas o demandas específicos; continuar trabajando para divulgar las ideas del feminismo; promover discusiones públicas sobre temas urgentes en el momento actual y acompañar a jóvenes que esperan hacer su propia contribución es mi manera de hacer activismo" (CAPOTE, 2017, s. p.).

29 Particularmente con algunos muy activos en el tema de género, como Afrocubanas, la Red de Mujeres Afrodescendientes, la Red Barrial Afrodescendientes, el proyecto Nosotrxs, y el Club del Espendrú. 
participan instituciones estatales (como la FMC y el CENESEX) junto con ONGs y activistas. Bajo el paraguas de estas alianzas o como iniciativas independientes, el repertorio del movimiento ha incluido producción académica, proyectos culturales, jornadas y campañas.

Han ido evolucionando de los discursos y la introducción de la perspectiva de género en la educación y la cultura, hacia acciones más independientes. Al igual que el movimiento afro, primero logran articular un subactivismo en espacios físicos y virtuales ${ }^{30} \mathrm{y}$ recientemente transitan hacia acciones como atención y asesoría a víctimas $^{31}$. En los últimos años el repertorio se ha enriquecido con acciones performáticas como como las realizadas por el proyecto Todas Contracorriente ${ }^{32}$; plataforma desde la cual en 2017 se convocó a una caminata performance que recorrió varias calles de la Habana, con música de salsa, para cerrar la Jornada Internacional por la no Violencia hacia las Mujeres y las Niñas. Otros performances artísticos más recientes replican acciones de feministas de otras latitudes como las intervenciones de reconocidas artistas en espacios públicos (el estadio de Béisbol o en un centro comercial) usando el arte y la música en la lucha contra la violencia de género, y la versión cubana de "Un Violador en tu Camino" en 201933.

Estas acciones y la introducción de nuevas PAD han generado un activismo que no necesita de alianzas ni auspicios estatales y que incluye entre sus estrategias la recogida de firmas y la movilización alrededor de sus campañas en plataformas virtuales como \#YoSíteCreoenCuba. Este nuevo activismo digital junto a la presentación de una solicitud formal a la Asamblea Nacional del Poder Popular (ANPP), de una Ley contra la Violencia de Género, puede considerarse el punto de inflexión que marca su paso una nueva etapa. La solicitud, firmada por 40 mujeres, fue entregada a la ANPP en

30 Desde 2005 han surgido blogs y sitios web feministas como Feminismos, Asamblea Feministay Alas Tensas, entre muchos otros.

31 La Red de Consejería para las Mujeres en Situación de Violencia del centro OAR y la creación en 2018 del primer Gabinete Jurídico para Acompañar a Víctimas.

32 Creado en 2011 por la cantante Rochy Ameneiro, que ha celebrado diversas giras artísticas nacionales. Cuenta con el apoyo de la Red Iberoamericana de Masculinidades, la Casa del Alba y la FMC.

33 El video puede verse en https://www.youtube.com/watch?v=RZkb5TNqNCs. 
noviembre de $2019^{34}$ y, luego, a través de la plataforma \#YoSíteCreoenCuba recogieron más de mil firmas de apoyo. Aunque la ley no ha sido incluida en el cronograma legislativo de la Asamblea, sí lograron que 4 de las firmantes fueran convocadas a una reunión con los presidentes de 3 comisiones y la encargada de la Oficina de Atención a la Población del parlamento; lo que evidencia mayor reconocimiento estatal y apunta a una modificación de la relación con las instituciones del Estado.

\section{El movimiento $L G B T I$}

El movimiento LGBTI también surge de la reunión de personas gay y transexuales, primero en algunos proyectos artísticos (como el show de travestis del club El Menjunje) y luego en foros intelectuales. En este caso también existió una organización que fue desactivada por el Estado (la Asociación Cubana de Gays y Lesbianas funcionó de 1994 a 1997). En 1998 se celebraron las primeras Jornadas de Arte Homoerotico (1998) donde por primera vez la literatura, el cine y el ensayo abordaron el tema gay; fueron promovidas por artistas e intelectuales para visibilizar homofobia y discriminaciones ${ }^{35} \mathrm{y}$ apoyadas por la UNEAC y el Ministerio de Cultura, logrando poner a circular en el espacio público un tema que hasta entonces había sido tabú en la sociedad cubana ${ }^{36}$.

Con la inclusión de la temática en el CENESEX (2007) el activismo LGBTI floreció y encontró legitimidad, aunque a costa de su independencia, ya que, en esta dinámica colaborativa tendió a fusionar sus agendas con los programas de esa institución estatal, la

34 Decidieron no usar la iniciativa legislativa (art. 164, de la Constitución), sino presentar una petición a la ANPP. Lo engorroso del trámite (se necesitan 10 mil firmas notariadas) hace muy difícil este tipo de acción para movimientos que no cuentan con financiamientos ni infraestructuras organizativas. No se puede descartar que al desechar esta opción también hayan querido desmarcarse del uso que le dio en su momento a este artículo constitucional el Proyecto Varela.

35 Por esta época también se discutía sobre la necesidad de que el sistema de salud pública realizara cirugías de reasignación de sexo.

36 El Estado cubano no solo había sido reacio al tema, sino que había perseguido a los homosexuales. En los 60 s y 70 s miles de ellos fueron internados en campos de trabajo y/o expulsados de sus centros laborales y de estudios. 
cual, desde entonces, atiende (agrupa y auspicia) varias redes comunitarias de todo el país ${ }^{37}$ y celebra las Jornadas contra la Homofobia ${ }^{38}$.

Los logros obtenidos por la comunidad a través de esta colaboración, como las operaciones gratuitas de cambio de sexo, la incorporación de la apariencia real en documentos de identidad, y el apoyo a campañas y redes de activistas, hizo que las relaciones con el Estado fueran fluidas y de gran aceptación por parte de la comunidad. Las acciones y campañas contra la homofobia, por la no discriminación, el derecho a igualdad en el empleo, la educación contra perjuicios en escuelas, por la inclusión en el código penal de la figura de crímenes de odio y la elaboración de cartas abiertas a la ANPP, fueron todas acciones que se abordaron desde el CENESEX o en colaboración con él. El gran peso del CENESEX como "patrocinador" (ROSSI, 2015) de las agendas del movimiento se ha combinado con que algunos de los activistas han ocupado $\mathrm{u}$ ocupan cargos en esa institución, la cual ha llegado a impulsar la candidatura a diputado de un ciudadano gay $^{39}$, con lo que se configura un activismo institucional. Por ello, este es el caso más exitoso de colaboración y el que más se asemeja al documentado en otros contextos nacionales (ABERS; TATAGIBA, 2015; ROSSI, 2015; ABERS; SERAFIM; TATAGIBA, 2014). El lado negativo de esta dinámica colaborativa es que la agenda se ha subordinado a lo que ese organismo aprueba y prioriza y los activistas están sometidos a sus decisiones a la vez que limitados en su capacidad de incidir

37 Entre ellas la Red de Jóvenes por la Salud y los Derechos Sexuales, la Red de Personas Transgénero, la Red de Mujeres Lesbianas y Bisexuales, Humanidad por la Diversidad y la Red de Juristas por los Derechos Sexuales.

38 También las jornadas por el Día Mundial de la Salud Sexual y Por la No Violencia contra las Mujeres y el Día Mundial de Respuesta al VIH.

39 El diputado, que fue electo en 2018, recientemente ha anunciado su renuncia por diferencias con el CENESEX. “Luis Roble es el único diputado abiertamente homosexual en la Asamblea Nacional de Cuba, y podría renunciar a su puesto después de que se le fuera negada la evidencia sobre su carrera como activista para asistir a un congreso en Bogotá [...]Para recibir la beca que se le fue otorgada y asistir al congreso donde se tratarían temas importantes dentro de la comunidad LGBTQI+, se requiere de un documento que defienda su trabajo como activista otorgado por el Centro Nacional de Educación Sexual, el cual está a cargo de Mariela Castro, hija de Raúl Castro. El organismo no dio una respuesta ante dicha petición" (DÍAZ, 2019, s. p.). 
sobre las políticas públicas. Todo ello ha motivado la emergencia de un activismo independiente que crece y se visibiliza cada vez más:

Para el activista Maykel Vivero, hoy existen al menos dos tipos de activismo LGBTIQ en Cuba: 'el vinculado a las instituciones, que lidera el CENESEX y el de personas y grupos independientes, no siempre reconocidos a pesar de su actuación permanente. Esta polaridad, desbalanceada, limita la efectividad de nuestros empeños comunes', afirma. Por su parte, el abogado del CENESEX y activista Manuel Vázquez Seijido reconoce la existencia y el valor de un 'activismo de las instituciones'. 'Yo puedo hablar desde el activismo con el que estoy relacionado, ese que busca la alianza con estructuras estatales como una vía inteligente y lógica para lograr el reconocimiento y garantía de nuestros derechos'. (GORDILLO PIÑA, 2015, s. p., mi subrayado).

En los últimos años han aparecido nuevas PAD, así como asociaciones y proyectos que buscan independencia del CENESEX como el Proyecto Arcoíris (2011), Abriendo Brechas de Colores (en colaboración con iglesias cristianas), las plataformas web Dame la Mano y Entre Diversidades (red para debatir y socializar temas LGBTI, surgida al calor de los debates constitucionales en 2019). Este activismo independiente enriquece el repertorio e integra nuevas estrategias como las besadas públicas en las calles, la convocatoria a reunirse en espacios públicos para formar con sus vestimentas la bandera del arcoíris y, la que constituye la más mediática e innovadora: la realización de la primera marcha gay no autorizada. Todas ellas convocadas y viralizadas en las redes sociales.

Respecto a la marcha, el 10 de abril de 2019, coincidiendo con la cancelación por parte del CENESEX de la Conga contra la Homofobia y en el contexto del gran debate sobre la inclusión del matrimonio igualitario en la Constitución, un activista independiente publicó en su cuenta de Facebook una convocatoria a una marcha independiente ("Hagamos nuestra propia marcha con el lema Los Derechos No se Plebiscitan”) que se replicó rápidamente a través de 
WhatsApp y Twitter. El 11 de abril se congregaron en el Parque Central varios cientos de personas dispuestas a caminar festivamente hasta el malecón habanero. La marcha fue disuelta por la policía y algunos participantes fueron detenidos, mientras el CENESEX la desautorizaba, tildándola de provocación orquestada desde Miami (DE LA CANTERA TORANZO, 2019; IPS, 2020). A pesar de ello, los activistas la consideran un "día histórico", "el Stonewall de Cuba" y la han proclamado el Día del Movimiento LGBTIQ cubano (DE LA CANTERA TORANZO, 2019), celebrando este año su primer aniversario.

\section{Animalistas}

Este movimiento también comparte algunos rasgos con los otros. Comienza en 1988 con la fundación de ANIPLANT, una asociación que cuenta con un mecanismo de intermediación institucionalizada en el Ministerio de Agricultura ${ }^{40}$. Dado el requisito de la ley de asociaciones vigente, es la única reconocida por el Estado. En un primer momento ANIPLANT dirigió peticiones a las autoridades, a través de comunicaciones dirigidas a ministros y funcionarios. Aunque recogieron firmas para una ley de protección animal no la llegaron a formalizar ya que aceptaron la respuesta de las autoridades de que "no era el momento" (BARÓ, 2018). Desde un inicio privilegiaron la colaboración estatal, lo que a la postre hizo que fuera percibida por otros protectores como una organización alejada del sentir de la sociedad civil. Por ello, en 2012 surgieron Protección Animal de Cuba (PAC), Cubanos en Defensa de los Animales (CEDA) en 2016 y colectivos por todo el país (ninguno de ellos tiene reconocimiento). Estas asociaciones han renovado el repertorio del movimiento, ya que no solo hacen labores de rescate de animales callejeros y campañas de esterilización (como ANIPLANT) sino que tienen una activa participación en el Internet y las redes sociales y gran presencia en las calles.

El acceso a internet a través de la señal wifi en lugares públicos en 2016 y luego la llegada definitiva de los datos móviles

40 El Departamento Independiente de Asociaciones, en el cual participan. 
en 2019, posibilitó que muchas personas conocieran más el accionar de los grupos protectores de animales y que sus diferentes mensajes tuviesen mayor alcance e inmediatez. Las redes sociales devinieron en una herramienta esencial en este proceso. (GONZÁLEZ CONSUEGRA, 2020, s. p.).

Enfocados en la promoción de nuevos valores éticos, junto al trabajo práctico en refugios, la acogida temporal de animales y las campañas de esterilización y atención veterinaria, enfatizan en el desarrollo de la conciencia ciudadana, con lo cual han articulado un subactivismo alrededor de una relaboración de valores. Después de 2018 han amplificado sus acciones y reclutado a más activistas e incorporado al repertorio las marchas y las protestas. Recientemente han creado la Red Bienestar Animal de Cuba (para articular a los diferentes grupos de protectores del país). Han desplegado una intensa campaña en demanda de una ley de protección animal (recogieron más de 10 mil firmas) y ha sido el único de los movimientos que ha logrado autorización para una marcha y que ha podido realizar una protesta pública sin represión policial. En ambas acciones, así como en sus redes sociales, los animalistas insisten en el carácter no político de su movimiento ${ }^{41}$ y su distancia de las organizaciones disidentes ${ }^{42}$.

Las autoridades cubanas tienen que confiar en nosotros, comprender que nuestro interés es salvar a los animales. Que necesitamos vías y condiciones para hacer nuestra labor, para

41 "El movimiento animalista cubano es autóctono, espontáneo y legítimo. Se ha construido sobre bases de amor y solidaridad, y con el sacrificio de muchas personas que poco tienen y lo dan todo [...] es injusto y poco serio etiquetar al movimiento animalista cubano, en su generalidad y diversidad, como un grupo de presión creado y orientado por el gobierno de los Estados Unidos para subvertir la realidad cubana, por el solo hecho de que los animalistas usen las redes para criticar indiferencias o denunciar casos de maltrato." (GONZÁLEZ CONSUEGRA, 2020, s. p., mi subrayado)

42 Al referirse a la presentación de la iniciativa de ley, el abogado Alan González subrayaba la diferencia: "Nos estamos introduciendo en un territorio prácticamente virgen: por un lado, las escasas normativas en cuanto a la protección animal en la Isla se establecieron antes de 1959; por otro, en varias ocasiones los ciudadanos han propuesto un modelo legal a partir de la recogida de firmas, y nunca fructificaron. El caso más conocido fue el Proyecto Varela, con perspectivas políticas y con intereses distintos a nuestro programa" ( PADRÓN CUETO, 2016, s. p.). 
canalizar donaciones, para recibir medicinas y recursos que son muy difíciles de conseguir en Cuba, y que eso no significa que seamos financiados desde el exterior con una intención política. Deben saber que no tenemos nada que ocultar y que lo que es a favor de los animales no es en contra del gobierno. (CARABALLOSA, 2020, s. p., mi subrayado).

Los activistas de PAC obtuvieron autorización del gobierno de La Habana para lo que calificaron como "la primera marcha no oficialista en décadas autorizada a portar carteles en el país" (EFE, 2019, s. p.). El 7 de abril de 2019 cientos de personas acompañadas por sus mascotas, recorrieron pacíficamente las calles de El Vedado con carteles alusivos al maltrato y el bienestar animal. La marcha se convocó y difundió por Facebook, Twitter y WhatsApp ${ }^{43}$.

En otro hecho sin precedentes, el 11 de noviembre de 2019, un grupo de activistas realizó un plantón frente a la sede del "Centro de Observación Canina, Zoonosis” en protesta por la recogida de perros para su sacrificio y por el derecho a la vida de los animales. En esta ocasión los activistas decidieron organizar la protesta de manera discreta y solo usaron mensajes de WhatsApp para acordar la fecha y la hora ${ }^{44}$. Una vez instalados allí, compartieron su presencia por las redes y convocaron a un twitazo con los hashtags: \#LeyDeProtecciónAnimalCubaYa, \#ZoonosisAsesinos y \#ZooNazis, sumándose algunos vecinos y otros activistas (DE LA CANTERA TORANZO, 2019). Aunque estuvieron bajo vigilancia policial, en este caso (a diferencia de la marcha gay) no hubo intervención de las fuerzas del orden, sino que lograron un diálogo con las autoridades cuyo

43 Una de las asistentes entrevistadas por la prensa declaraba que lo nutrido de la concurrencia era "resultado de la exitosa campaña del grupo en redes sociales y la creciente interacción ciudadana en Twitter. Es increíble cómo ha crecido el activismo ahora que tenemos datos móviles y podemos conectarnos" (EFE, 2019, s. p.).

44 Según los activistas el propósito era lograr"una manifestación que, en primera instancia, lograra realizarse y que, en segunda, no diera lugar a posibles interpretaciones de desorden público. Decidieron no compartir la convocatoria en redes sociales. Optaron por un grupo pequeño pero efectivo [...], explicó a YucaByte Sergio Boris Concepción Silva, uno de los activistas presentes en la protesta y luego en la reunión con las autoridades [...] Queríamos una manifestación pacífica, en la que no hubo consigna, en la que no se gritó, en la que los carteles hablaban". (DE LA CANTERA TORANZO, 2019, s. p.). 
resultado fue el rescate de 11 perros y el acuerdo de realizar al siguiente día una reunión entre 12 activistas y los funcionarios para expresar sus demandas y reclamos.

En el caso del movimiento animal la dinámica de colaboración con el Estado se circunscribe a una sola de las organizaciones (ANIPLANT) que tiene presencia y diálogo con el Ministerio de Agricultura, el resto de las organizaciones realiza sus acciones y campañas con total independencia del Estado. En este sentido, la dinámica colaborativa es un tanto diferente de la que han desplegado los otros movimientos cuyas agendas específicas son incluidas en campañas y organismos estatales (violencia de género, discriminación racial o derechos sexuales) ya que ninguna institución estatal promueve la protección animal. A pesar de ello, y aunque los activistas independientes también sufren la sospecha y la desconfianza, es el movimiento que ha logrado mayor tolerancia estatal a sus manifestaciones públicas (caso de la protesta ${ }^{45}$ ) y a su petición de legislación (inclusión en el cronograma legislativo de la ANPP de un Decreto-Ley de Bienestar Animal a presentarse en noviembre del 2020).

\section{La nueva constitución y la activación de un nuevo repertorio}

Observando cronológicamente el desarrollo de los movimientos, se evidencia que el crecimiento del activismo y las innovaciones en sus repertorios de estrategias coinciden con el proceso de cambio constitucional y el uso extendido de las redes sociales, lo que permite afirmar que, si los cambios socioeconómicos de los últimos 30 años configuran el contexto general de esas trayectorias, el proceso de reemplazo constitucional le confiere una impronta particular.

El proceso inició en agosto de 2018, con la discusión del Proyecto de Constitución, presentado por la ANPP para someterlo a debate en asambleas barriales, centros laborales, de estudios, etc. Esta

45 Aunque ha trascendido que el funcionario que autorizó la marcha de abril de 2019 fue destituido de su cargo días después y que intentos por replicar la marcha en otras provincias, no obtuvieron autorización y un joven activista de Santa Clara enfrentó un proceso disciplinario en su Universidad por solicitarla. 
consulta no solo fue significativa en términos de la cantidad de personas involucradas sino también en cuanto al número y el tipo de planteamientos recogidos. Según datos presentados a los diputados, se realizaron 133 mil 681 reuniones, a las cuales asistieron casi 9 millones de personas que realizaron un millón 706 mil 872 intervenciones y 783 mil 174 propuestas $^{46}$ (CUBADEBATE, 2018). Estas cifras dan una idea de lo intenso y masivo que fue el proceso de discusión, pero lo que interesa subrayar aquí, más allá de la cantidad, es que los planteamientos e intervenciones reflejaron el aumento de la diversidad social y la pluralidad de intereses ${ }^{47}$.

El debate no se limitó a las reuniones y asambleas, sino que se extendió a los medios independientes ${ }^{48} \mathrm{y}$ a las redes sociales. Facebook, WhatsApp, Twitter, se impusieron como espacios alternativos donde continuar y profundizar la deliberación colectiva sobre la nueva Constitución. Allí, entre los muchos temas, afloraron los de discriminación y racismo, derechos de asociación, igualdad, derechos reproductivos, violencia familiar y feminicidios, y el bienestar animal, por lo que este proceso de consulta popular amplificó las opiniones de los activistas. Los propios activistas usaron las recién estrenadas conexiones por datos móviles (mucho más dinámicos y con mayor alcance que el correo electrónico) para viralizar sus mensajes y ocupar un espacio destacado en el debate.

Hay que recordar que este debate estuvo precedido por la intensa producción discursiva y el subactivismo de los movimientos a favor de nueva maneras de ver el racismo, la discriminación, el género y la violencia contra las mujeres, los derechos sexuales y el bienestar

46 Una vez terminada la discusión, el proyecto fue reelaborado por la ANPP y aprobado en referendo por el $86.8 \%$ de los electores (febrero de 2019).

47 Estas cifras rebasan por mucho, la tradición cubana de ratificación casi unánime de las propuestas sometidas a consulta por parte de las autoridades. Nótese la diferencia con el proceso constitucional de 1976 donde más de 6 millones de personas participaron en la discusión del proyecto, hubo solo 16 mil propuestas de modificaciones y adiciones, y 5 y medio millones votaron a favor de mantenerlo igual (CASTRO, 1975). "Distinto al repertorio de la política cubana del pasado reciente, caracterizado por la unanimidad o la desidia, el futuro orden constitucional se disputó. Al documento se le realizaron 760 enmiendas, que transformaron el $60 \%$ del texto inicialmente propuesto" (TORRES SANTANA, 2019, s. p.).

48 Pueden consultarse, por ejemplo, los dosieres sobre el proceso que compilaron los medios digitales independientes El Toque (EL TOQUE, 2019) y Cuba Posible (DOMÍN GUEZ et al., 2020). 
animal; discursos que no solo habían circulado en la web, sino que, dada la dinámica colaborativa con instituciones gubernamentales, se habían logrado introducir a los espacios controlados por el Estado y a la opinión pública a través de foros académicos, intelectuales y artísticos, las jornadas contra la homofobia, el racismo y la violencia de género. Todas ellas, aunque dirigidas o auspiciadas por instituciones gubernamentales, llevaban la impronta de los valores y agendas que los movimientos habían introducido. Por tanto, la inclusión de los temas y discursos de los movimientos ocurrió en un imaginario social ya diversificado e independizado del discurso oficial.

El llamamiento del gobierno a la población para que participara masivamente en el proceso confirió legitimidad a los planteamientos identitarios y la consultadevino un foro legitimado y autorizado para su discusión pública. La intensa campaña oficial que llamaba a votar por el Sí e identificaba Constitución y Socialismo permitía ubicar simbólicamente estos reclamos dentro del sistema. En esta circunstancia, los movimientos vieron en la consulta no solo un espacio propicio para pensar y discutir sus temas y problemáticas específicas, sino la posibilidad de llevarlos tanto a la agenda social como al ámbito normativo ${ }^{49}$. En un debate realizado en la Red de Mujeres Cubanas Afrodescendientes, se discutió acerca de la necesidad de "Ampliar el activismo por los derechos de las personas negras, eliminar el lenguaje sexista y profundizar en la no discriminación dentro del proyecto de nueva Constitución cubana" (IPS, 2018, s. p.). Asimismo, las feministas discutieron sobre los avances y retrocesos del proyecto para su agenda (TORRES SANTANA, 2019) y los animalistas introdujeron el tema de los derechos de los animales.

49 "Previo a los debates del parlamento, uno de los esfuerzos ciudadanos más notables se formuló en un documento colectivo que listaba demandas específicas a quienes tienen potestad constituyente. El documento atendía a derechos y garantías para las personas de la comunidad LGTBIQ. Entre ellas, el matrimonio igualitario y cambios que aseguren la no discriminación por orientación sexual o identidad de género. El texto realizó propuestas concretas respecto a artículos constitucionales y a normas legales como el Código de Familia o Código de Trabajo". (TORRES SANTANA, 2018, s. p.) 
Cuando se supo, a mediados de 2018, el alcance de las transformaciones que se proponían para la nueva Constitución cubana, pensamos que era la oportunidad perfecta para que nuestra Carta Magna se pronunciara sobre la protección animal como lo había hecho en su momento la de la República de Ecuador en 2008, durante el gobierno de Rafael Correa, y otras de larga data en el mundo [...] Si bien no se logró que la comisión redactora apostase por la inclusión expresa de la protección y del bienestar animal en el articulado del texto constitucional, todo el debate que generaron las propuestas que circulamos los animalistas en las redes sociales y los correos electrónicos, así como las formuladas por los propios ciudadanos en las asambleas, sirvió para poner el tema de una vez y por todas en la agenda pública. Los más de tres mil planteamientos generados en la consulta abrían las puertas a una futura normativa de protección y bienestar animal. (GONZÁLEZ CONSUEGRA, 2020, s. p.).

Más allá de estos ejemplos que hablan de la elección estratégica de los activistas, la evidencia más significativa de la introducción de los temas identitarios a la consulta es la centralidad alcanzada por el tema del matrimonio igualitario (Art. 68). Dentro de las opiniones expresadas por los ciudadanos que fueron presentadas a la ANPP, el Art. 68 ocupó el primer lugar (24.57\% del total) (FIGUEREDO, 2018), siendo mencionado en 88,066 reuniones y alcanzando más de 192,408 propuestas (CUBADEBATE, 2018).

En esta disputa emergió la articulación y visibilidad de actores sociales antagónicos al feminismo y al movimiento LGBTI. Iglesias evangélicas (y también la católica) por primera vez ${ }^{50}$ desplegaron un muy activo repertorio que se materializó en campañas bien estructuradas y financiadas contra la ideología de género y a favor

50 Si bien desde los 90s las iglesias habían mejorado su relación con el Estado y aumentado su presencia en la sociedad a través del trabajo filantrópico y de asistencia social, y tenían ONGs reconocidas y con registro, nunca antes habían salido y contendido de esa forma en el espacio público con otros actores de la sociedad civil. 
de la "Familia Original". Este activismo fundamentalista religioso desplegó su campaña de oposición al matrimonio igualitario no solo en los templos, sino que irrumpió en sitios públicos con carteles, prédicas en mercados y otros lugares concurridos. Los activistas LGBTI y las feministas respondieron con su campaña por "Una familia MUUY original" y el hashtag \#MiFamiliaEsMuyOriginal, la cual motivó acciones performáticas (como las besadas públicas) y expresivas (caminatas de parejas del mismo sexo tomadas de la mano), convocadas y organizadas en Internet. Lo más significativo de esta experiencia fue la identificación por parte de los activistas de un actor antagonista en la sociedad civil, no estatal, organizado y con capacidad de movilización, que se cohesionó y articuló alrededor del debate.

La respuesta estatal a la propaganda y el activismo de las iglesias no fue represiva, lo cual repercutió también sobre los repertorios de los movimientos en otros dos sentidos. En primer lugar, ante esta arremetida de las zonas conservadoras de la sociedad, los movimientos LGBTI y feministas (y sus aliados en el movimiento afro) se vieron enfrentados a reevaluar su relación con el Estado. Éste no sólo fue permisivo y aquiescente respecto a la irrupción conservadora en el espacio público, sino que al final la ANPP optó por no incluir el artículo en la nueva constitución ${ }^{51}$, lo que resintió la dinámica colaborativa y alentó un activismo independiente, vigorizado y renovado con el despliegue de un repertorio digital que fue más allá de la difusión de su campaña en la red, utilizando las herramientas digitales para organizar sus acciones off line (performances y marcha). En segundo lugar, la disputa contribuyó a activar la conciencia de los activistas acerca de la necesidad de una legislación para proteger los avances logrados y no ceder el espacio a sus oponentes.

Tanto la convocatoria como el proceso deliberativo en torno al proyecto de Constitución incentivaron el interés por el orden legal e indujeron la discusión sobre el rol de la ley y la institucionalidad,

51 La propuesta del gobierno es incluirla en el Código de Familia (previsto en el cronograma legislativo para diciembre de 2021) si fuera aprobado antes en un referendo convocado al efecto. Los activistas han expresado su desacuerdo, argumentando que "los derechos no se plebiscitan". 
enfatizando la importancia de la dimensión normativa y la legalidad. A esto se suma que la nueva Constitución, mandata a la ANPP establecer y publicar (por primera vez en su historia) su cronograma legislativo, lo que además de dar relevancia a la función legislativa como asunto de interés público, ha permitido a los movimientos monitorear el lugar de sus pendientes en la agenda parlamentaria y demandar la inclusión de sus reclamos. Las respuestas estatales del último año a las demandas de los movimientos ${ }^{52}$ y la inclusión en el cronograma de una legislación secundaria que han demandado los activistas (de protección animal, sobre derechos de manifestación y reunión y ley de identidad); parecen inscribirse en este proceso.

Otro elemento que influye sobre las innovaciones en el repertorio está en el propio texto constitucional. La constitución aprobada contiene varios cambios significativos que influyen sobre la conciencia de los activistas en torno a la importancia del derecho y la posibilidad de influir en las decisiones del gobierno por la vía de impulsar nueva legislación ${ }^{53}$. La nueva formulación del Art. 1 que define al Estado cubano como "Estado socialista de derecho" (ANPP, 2019) y la introducción de un lenguaje de derechos humanos ${ }^{54}$, constituyen cambios de gran impacto que permiten a los movimientos colocar sus demandas en un marco legal. Otros avances favorables son el Art. 56 que garantiza los derechos de reunión y manifestación con fines lícitos y pacíficos siempre que se ejerzan con respeto al orden público y la ley (se eliminó el condicionamiento a su práctica a través de organizaciones de masas

52 Me refiero a la reunión con las demandantes de la ley contra la violencia de género y la respuesta de la ANPP de transversalizar el tema en varias de las leyes previstas; y a la creación del Programa Nacional contra la Discriminación Racial.

53 "Ahora estamos enfocados en la nueva Constitución. Desde que salió la consulta pública lo dijimos: este es el momento. En la otra Constitución no dieron oportunidad de opinar. Esta va mucho más democrática. Además, es obligatorio elevar todas las peticiones que se hagan. Tenemos que hacer el intento." (Entrevista a Presidenta de ANIPLANT) (BARÓ, 2018, s. p.).

54 "ARTÍCULO 41. El Estado cubano reconoce y garantiza a la persona el goce y el ejercicio irrenunciable, imprescriptible, indivisible, universal e interdependiente de los derechos humanos, en correspondencia con los principios de progresividad, igualdad y no discriminación. Su respeto y garantía es de obligatorio cumplimiento para todos." (ANPP, 2019, s. p.) 
que tenía la Constitución anterior $)^{55}$, el Art. 80 sobre el derecho a participar en la conformación y el ejercicio del poder y el Art. 10 que prescribe la obligación del Estado a atender peticiones y dar respuesta al pueblo.

La nueva constitución además, introduce nuevos derechos económicos y sociales (medio ambiente, agua, vivienda digna, consumidor, acceso a la información) y recoge algunos planteamientos identitarios (con mayor o menor cercanía a las posturas de los movimientos); entre ellos el Art. 42 sobre la igualdad (que incluye como motivos punibles la discriminación por sexo, género, orientación sexual, identidad de género, origen étnico, color de la piel); el Art. 43 donde el Estado garantiza los derechos sexuales y reproductivos y brinda protección ante violencia de género (debiendo crear mecanismos institucionales y legales para ello); el Art. 85 que especifica que la violencia de género es lesiva a las personas implicadas en ella y debe ser sancionada por la ley. También, como un logro para los animalistas, en el art. 90 se adicionó a la protección estatal de los recursos naturales una mención específica a la flora y la fauna.

Todas estas inclusiones legitiman las diversas identidades, respaldan que los activistas invoquen esos derechos en diversas acciones y en peticiones de leyes ${ }^{56}$, y estimulan la ampliación de los repertorios con estrategias que apuntan a la demanda de políticas públicas, lo que supone una conciencia en los actores de que sus reclamos tienen al menos una arista de naturaleza legal y de la posibilidad de que se remedie por vía legal (McCANN, 2006; ZEMANS, 1983) y, en particular, con la promulgación de una ley. Desde esta perspectiva, lo que se había definido como carencias o rezagos del pasado se puede reinterpretar como violaciones a los derechos consagrados en la Constitución y relacionarse con decisiones y políticas gubernamentales. Los movimientos están comenzando

55 El artículo quedó reformulado así: "Los derechos de reunión, manifestación y asociación, con fines lícitos y pacíficos, se reconocen por el Estado siempre que se ejerzan con respeto al orden público y el acatamiento a las preceptivas establecidas en la ley." (ANPP, 2019, s. p.)

56 Tanto la marcha animalista como la LGBTI aludieron al Art. 56; mientras que el documento de solicitud de Ley Integral contra la Violencia de Género invoca el Art. 61 (sobre el derecho de petición), el Art.43, el Art.41, el Art. 44 y el Art. 86 (referido a la protección de los niñ@s contra todo tipo de violencia). 
a apelar al sistema normativo para construir sus demandas invocando derechos legales, con lo cual, el reemplazo constitucional que intenta reforzar la dimensión de control social del sistema legal (del gobierno a la sociedad), tendría como consecuencia no esperada el fortalecimiento implícito de su dimensión de cambio social, es decir, la posibilidad del uso de la ley por parte de la sociedad. En este caso si el poder se (re)legitima y justifica sus acciones a partir de los nuevos preceptos constitucionales, los movimientos también pueden usarlos para articular sus demandas y reclamos.

Esto se combina de manera virtuosa con el aumento de la conectividad y las nuevas PAD. El uso de las herramientas digitales facilita las peticiones de leyes y políticas. Los activistas usan plataformas digitales, tanto creadas por ellos para movilizar en torno a temas específicos (como \#YoSíteCreoenCuba), o bien utilizando las ya existentes en la web (como Change.Org ${ }^{57}$ ). Estas campañas on line simplifican las recolecciones de firmas, permiten llegar más rápidamente y con menor costo a un grupo mucho mayor de potenciales adherentes y abarcar todo el país.

No obstante, este escenario propicio a las innovaciones y el empoderamiento de los movimientos es bastante frágil y aún persisten muchos obstáculos y restricciones a su actuación autónoma y contenciosa: En primer lugar, respecto al uso de las PAD, se ha demostrado que la difusión de sus mensajes en comunidades virtuales puede generar un activismo de bajo compromiso, pasivo e inofensivo (slacktivismo), de poco valor para los movimientos (SÁNCHEZ-DUARTE; FERNÁNDEZ ROMERO, 2017; VON BÜLOW, 2018). A su vez, el Estado ha mostrado que también está dispuesto a usar esas herramientas para controlar y tutelar la actividad on line (censura de sitios web, monitoreo de publicaciones de Facebook de activistas y opositores, creación de sus propios sitios y blogs para contrarrestar los de los activistas) (HOFFMAAN, 2011). No hay que olvidar que,

57 En Change.Org se han promovido diversas peticiones, que solicitan desde el levantamiento del embargo, hasta la introducción de la protección animal en la Constitución, la disminución de los precios del Internet y los datos móviles, la ley contra violencia de género y los derechos LGBTI. El Estado cubano recientemente ha bloqueado el acceso a ella desde la Isla. 
si bien las PAD facilitan a los movimientos evadir los obstáculos y restricciones, los gobiernos también pueden usar la tecnología para la vigilancia y la obstrucción (EARL, 2019).

En segundo lugar, aunque la Constitución refrenda la igualdad y prohíbe la discriminación por sexo, género, orientación sexual, identidad de género, origen étnico, color de la piel, creencia religiosa, discapacidad, origen nacional o territorial, no incluye la acción afirmativa, y ni siquiera menciona a los grupos que han reclamado desde hace algunos años la existencia de estereotipos, prejuicios y conductas discriminatorias contra ellos (como los afrocubanos y las personas LGBTI $)^{58}$. Adicionalmente, la permanencia de prescripciones en torno a fortalecer la unidad nacional (Art. 13) y la afirmación de que las organizaciones de masas agrupan a los distintos sectores de la población y representan sus intereses específicos (Art. 14), conspira contra el reconocimiento de la pluralidad y la posibilidad de asociaciones más específicas de articulación de intereses particularistas (no contemplados en las organizaciones de masas).

A esto se suma que la nueva constitución presenta un déficit de derechos organizacionales (de reunión, de sindicalización y a formar partidos políticos), así como de derechos colectivos y de grupos. A pesar de la introducción de derechos difusos (medio ambiente, consumidor, etc.) la titularidad sigue siendo individual ${ }^{59}$ y no contempla derechos colectivos de petición o garantías de amparos ni medidas de protección colectivas.

Por último, la mayoría de estos derechos están sujetos a una reglamentación por leyes secundarias que no han sido aprobadas y que podrían limitarlos y restringirlos. Los activistas siguen esperando por una nueva ley de asociaciones que se ha postergado hasta julio de 2022. Asimismo, es preciso esperar a conocer el contenido de otras leyes previstas en el cronograma legislativo, como es el caso

58 La mención de estos grupos por su nombre no es un asunto menor, ya que es un modo de superar las declaraciones abstractas de igualdad y la prohibición de la discriminación. Esta alusión constituye una forma de reconocimiento simbólico que legitima la asignación de recursos a grupos excluidos.

59 Por ejemplo, el Art. 61 establece que las personas tienen derecho a dirigir quejas y peticiones a la autoridad. 
del Decreto Ley sobre derechos de manifestación y reunión, para evaluar si se ampliarán los espacios y oportunidades legales para los movimientos o si por el contrario la legislación secundaria los condicionará o constreñirá aún más.

\section{Reflexión final}

En los últimos años el escenario de cambio constitucional y ampliación del de acceso a las redes sociales, en conjunción con los aprendizajes derivados de sus stocks de legados y experiencias pasadas, han conformado una coyuntura favorable para que, a partir de la renovación de sus repertorios y la introducción de nuevas estrategias y acciones, los movimientos hayan reforzado su capacidad para interactuar con el Estado, articular demandas concretas, y posicionarse como interlocutores válidos y legítimos ante él. Esta capacidad se ha desarrollado sobre la base de pequeños avances resultado de algunas estrategias exitosas, como la elección de desplegar un repertorio de interacción y una dinámica colaborativa con el Estado en los espacios donde aquel lo ha permitido, su deslinde de organizaciones de oposición; así como las alianzas con ONGs que cuentan con reconocimiento estatal.

El debate y la aprobación de la nueva Constitución en un escenario de aumento de la conectividad a través del acceso a datos móviles ha permitido a los movimientos: ampliar su presencia e influencia en la esfera pública, reposicionarse en el espacio de la sociedad civil e identificar nuevos aliados y oponentes; así como pasar de los discursos de identidad y el subactivismo a reclamos de derechos y renovar sus repertorios de estrategias e interacción. Las nuevas estrategias incluyen el uso de acciones performáticas, la ocupación del espacio público a través de marchas y demostraciones y la articulación de demandas en términos de derechos y cambios legislativos. Todas ellas legitimadas por el nuevo marco normativo refrendado en la Constitución de 2019 -que amplía discretamente el ámbito para su acción-, y amplificadas por el uso de nuevas PAD -que elevan su capacidad de coordinación y movilización, difusión de sus temas y propuestas hacia la sociedad, dan mayor visibilidad 
a sus acciones, y contribuyen a diversificar sus capacidades de peticionar leyes y políticas específicas-.

Todo ello contribuye a modificar la relación Estado/sociedad y plantea nuevos desafíos: El Estado, que a través de su ideología de la unidad revolucionaria, la identificación de lo autónomo e independiente con lo contrarrevolucionario y pro yanqui, la descalificación de los financiamientos externos, la obstrucción de la presencia de los discursos y demandas de los movimientos en los medios de comunicación, ha sido exitoso en su neutralización de las autonomías; en el nuevo contexto de reforma económica, cambio social y normativo y acceso a Internet, ha flexibilizado mínimamente su postura, con lo cual, los movimientos ganan espacios, obtienen respuestas a algunas de sus demandas, y empiezan a mostrar cierto grado de empoderamiento,

No obstante, esta nueva forma de interpelación al Estado no está exenta de obstáculos y frenos, el mayor de los cuales (junto a la incertidumbre respecto al contenido de las leyes que regularán de manera específica el ejercicio de los derechos constitucionales y el modo en que la sociedad podría asociarse y manifestarse) es la pervivencia de un discurso de unidad y de nación en guerra, y la persistencia de una actuación represiva hacia cualquier conducta social que amenace el monopolio estatal sobre el espacio público y la sociedad.

\section{Referencias}

ABERS, Rebecca; SERAFIM, Lisandra; TATAGIBA, Luciana. Repertórios de interação Estado-Sociedade em um Estado heterogêneo: a experiência na Era Lula. DADOS - Revista de Ciências Sociais, [Online], v. 57, n. 2, p. 325-357, 2014.

ABERS, Rebecca; TATAGIBA, Luciana. Institutional activism: mobilizing for women's health from inside the Brazilian bureaucracy. In: ROSSI, Federico M.; VON BÜLOW, Marisa. Social movement dynamics. New perspectives on theory and research from Latin America. New York: Routledge, 2015. p. 73-103. 
ABERS, Rebecca; VON BÜLOW, Marisa. Movimentos sociais na teoria e na prática: como estudar o ativismo através da fronteira entre Estado e sociedade. Sociologias, Porto Alegre, ano 13, n. 28, p. 52-84, 2011.

AFROCUBAWEB. Articulación Regional Afrodescendiente de América Latina y el Caribe, Capítulo Cubano (ARAAC). Sitio eletrónico. S. d. Disponible en: http://www.afrocubaweb.com/. Acceso en: 27 feb. 2020.

ALMEIDA, Paul. Movimientos sociales: la estructura de la acción colectiva. Buenos Aires: CLACSO, 2020. Libro digital. Disponible en: https://www.clacso.org/movimientos-sociales-la-estructurade-la-accion-colectiva/. Acceso en: 2 oct. 2020.

ALONSO, Randy. Informe Global Digital 2019: Cuba entre los países que más crecen en usuarios de internet y redes sociales. Cubadebate, [Online], 13 de febrero de 2019. Disponible en: http://www.cubadebate.cu/especiales/2019/02/13/informeglobal-digital-2019-cuba-entre-los-paises-que-mas-crecen-enusuarios-de-internet-y-redes-sociales/\#.Xs1lNflKjZq. Acceso en: 2 mayo 2020.

ANPP- Asamblea Nacional del Poder Popular. Constitución de la República de Cuba. [S. 1.]: ANPP, 5 enero 2019. Disponible en: http://media.cubadebate.cu/wp-content/uploads/2019/01/ Constitucion-Cuba-2019.pdf. Acceso en: 6 enero 2019.

ANPP- Asamblea Nacional del Poder Popular. Constitución de la República de Cuba de 1976. [S. l.]: ANPP, 1992. Disponible en: http://www.cervantesvirtual.com/obra-visor/constitucionde-la-republica-de-cuba-de-1976-incluye-la-reformaconstitucional-del-26-de-mayo-2002/html/d89469f5-2cfd4009-85ab-ba8540d6d5ec_2.html\#I_0. Acceso en: 15 sept. 2019. ANPP - Asamblea Nacional del Poder Popular. Ley de Asociaciones. [S. l.]: ANPP, 1985. Disponible en: http://www. parlamentocubano.gob.cu/index.php/documento/ley-deasociaciones/. Acceso en: 15marzo 2019. 
BAKARDJIEVA, Maria. Subactivism: lifeworld and politics in the age of the internet. The Information Society, [Online], v. 25, n. 2, p. 91-104, 2009.

BARÓ, Mónica. ¿Y la ley de protección animal para cuándo?. Guardabosques, [Online],15 oct. 2018. Disponible en: https:// guardabosquescuba.org/2018/10/15/y-la-ley-de-proteccionanimal-para-cuando/. Acceso en: 10 abr. 2020.

BOBES, Velia Cecilia. Civil society during and beyond the special period. International Journal of Cuban Studies, [Online], v. 5, n. 3, p. 168-183, 2013.

BOBES, Velia Cecilia. Entre la autonomía y el control: la sociedad civil. In: ROJAS, Rafael (coord.). Cuba hoy y mañana. Actores e instituciones de una política en transición. México, D.F.: Planeta; CIDE, 2005. p. 67-85.

BOBES, Velia Cecilia. Reformas en Cuba: ¿Actualización del socialismo o reconfiguración social? Cuban Studies, Pittsburgh, n. 44, p. 241-277, 2015.

CAPOTE, Zaida. Activismo académico. Tradición, práctica y testimonio. Asamblea Feminista, [Online], 17 mayo 2017. Disponible en: https://asambleafeminista.wordpress. com/2017/05/29/activismo-en-la-academia-las-rutas-delfeminismo-en-el-congreso-de-lasa-en-lima/\#more-269. Acceso en: 16 abr. 2020.

CARABALLOSA, Erick. Protectores de animales en Cuba: la voz de los sin voz. OnCuba News, [Online], $21 \mathrm{feb}$. 2020. Disponible en: https://oncubanews.com/cuba/protectores-de-animales-encuba-la-voz-de-los-sin-voz/. Acceso en: 22 feb. 2020.

CASTRO, Fidel. Informe Central. Primer Congreso del Partido Comunista de Cuba. La Habana: Departamento de Orientación Revolucionaria, 1975.

CHADWICKAndrew.Digitalnetworkrepertoiresandorganizational hybridity. Political Communication, Philadelphia, v. 24, n. 3, p. 283-301, 2007. Disponible en: https://www.tandfonline. com/doi/abs/10.1080/10584600701471666. DOI: https://doi. org/10.1080/10584600701471666. Acceso en: 23 sept. 2020. 
CHEN, Xi; MOSS, Dana M. Authoritarians regimes and social movements. In: SNOW, David A.; SOULE, Sarah A.; KRIESI, Hanspeter; McCAMMON, Holly J. (ed.). The Wiley Blackwell companion to social movements. 2. end. Hoboken: Wiley Blackwell, 2019. p. 666-681.

CHU, Lynette. J. Legal mobilization and authoritarianism. Annual Review of Law and Social Science, Palo Alto, v. 15, p. 355-376, 2019.

COMISIÓN JOSÉ ANTONIO APONTE. Boletín Aponte, n .64, abr.-ago. 2018. Disponible en: http://www.afrocubaweb.com/ boletin-aponte/Bolet\%C3\%ADn\%20Aponte\%20No.\%2064\%20 Abril-Agosto\%202018.pdf. Acceso en: 3 mayo 2020.

CUBADEBATE. Presentan a los diputados resultados de la consulta popular del Proyecto de Constitución. Cubadebate, [online], 18 dic. 2018. Disponible en: http://www.cubadebate. $\mathrm{cu} /$ noticias/2018/12/18/presentan-cambios-en-el-proyectode-constitucion-derivados-de-la-consulta-popular/\#. XswnPPlKjZo. Acceso en: 12 abr. 2019.

DE LA CANTERA TORANZO, Cynthia. Activismo por el bienestar animal en Cuba: lecciones de una "protesta sorpresa". YucaByte, [Online], 15 nov. 2019. Disponible en: https://www.yucabyte. org/2019/11/15/protesta-animalista-sorpresa/. Acceso en: 2 mayo 2020.

DE LA FUENTE, Alejandro. Tengo una raza oscura y discriminada. El movimiento afrocubano: hacia un programa consensuado. Nueva Sociedad, Buenos Aires, n. 242, p. 92-105, 2012.

DIANI, Mario. Revisando el concepto de movimiento social. Encrucijadas - Revista Critica de Ciencias Sociales, n. 9, p. 1-16, 2015. Disponible en: https://recyt.fecyt.es/index.php/ encrucijadas/article/view/79024 .Acceso en: 13 mayo 2020.

DÍAZ, Fa. Diputado gay cubano podría renunciar a su puesto. El Clóset LGBT+, [Online], 8 nov. 2019. Disponible en: https:// elclosetlgbt.com/noticias/diputado-gay-cuba/. Acceso en: 10 mayo 2020. 
DOMÍNGUEZ, Jorge I; VEIGA, Roberto; GONZALEZ, Lenier; ANGEL, Sergio. La Cuba que quisimos. La nueva constitución cubana de 2019: debates de Cuba Posible sobre su formulación, anteproyecto y proyecto final. Bogotá: Universidad Sergio Arboleda, 2020.

EARL, Jeniffer. Technology and social media. In: SNOW, David A.; SOULE, Sarah A.; KRIESI, Hanspeter; McCAMMON, Holly J. (ed.). The Wiley Blackwell companion to social movements. 2. ed. Hoboken: Wiley Blackwell, 2019. p 289-305.

EARL, Jennifer; KIMPORT, Katrina. Digitally enabled social change - activism in the internet age. Boston, MA: The MIT Press, 2011.

EFE. Cubanos marchan contra el maltrato animal en una manifestación permitida por el Estado. EFE, La Habana, 7 abr. 2019. Disponible en: https://www.efe.com/efe/america/ sociedad/cubanos-marchan-contra-el-maltrato-animal-enuna-manifestacion-permitida-por-estado/20000013-3946658. Acceso en: 25 abr. 2020.

EFE. El acceso a internet en Cuba llega a 7,1 millones de usuarios en 2019. EFE, La Habana, 26 feb. 2020. Disponible en: https:// www.efe.com/efe/america/tecnologia/el-acceso-a-internet-encuba-llega-7-1-millones-de-usuarios-2019/20000036-4182015. Acceso en: 14 mayo 2020.

EL TOQUE. La Cuba que viene. Claves para comprender la reforma constitucional. 2019. Disponible en: https://constitucion.eltoque. com/. Acceso en: 10 enero 2020.

ESPINA, Mayra. La política social cubana para el manejo de la desigualdad. Cuban Studies, Pittsburgh, n. 41, p. 20-38, 2010.

FIGUEREDO, Oscar. ¿Cuáles son los principales cambios en el Proyecto de Constitución? Cubadebate, [Online], 21 dic. 2018. Disponible en: http://www.cubadebate.cu/especiales/2018/12/21/ cuales-son-los-principales-cambios-en-el-proyecto-deconstitucion/\#.Xitlc_lKjqA. Acceso en: 2 dic. 2019. 
FOMINAYA, Cristina Flesher. Collective identity in social movements: assessing the limits of a theoretical framework. In: SNOW, David A.; SOULE, Sarah A.; KRIESI, Hanspeter; McCAMMON, Holly J. (eds.). The Wiley Blackwell companion to social movements. 2. ed. Hoboken: Wiley Blackwell, 2019. p. 429- 445.

FOWERAKER, Joe. Theorizing social movements. London/ Boulder: Pluto Press, 1995.

FUENTES PUEBLA, Thalía; GARCÍA ACOSTA, Dinella. Programa nacional contra el racismo y la discriminación racial: "Yo creo en el color cubano". Cubadebate, [Online], 11 mar. 2020. Disponible en: http://www.cubadebate.cu/especiales/2020/03/11/programanacional-contra-el-racismo-y-la-discriminacion-racial-yo-creoen-el-color-cubano/\#.XtxKoBdKhOo. Acceso en: 14 abr. 2020.

GÁMEZ, Nora. Activistas afrocubanos intentan romper tabúes raciales sin agotar paciencia oficial. El Nuevo Herald, [Online], 30 abr. 2017. Disponible en: https://www.elnuevoherald.com/ noticias/mundo/america-latina/cuba-es/article147136754.html .Acceso en: 14 abr. 2020.

GONZÁlEZ CONSUEGRA, Alan. Protección animal en Cuba: Introductio ad topic. 8 abr. 2020. Disponible en: https:// segundacita.blogspot.com. Acceso en: 8 abr. 2020.

GORDILLO PIÑA, Lirians. Hablando de activismo... más allá del deber. Entrevista con Maykel Vivero. Asamblea Feminista, [Online], 13 oct. 2015. Disponible en: https://asambleafeminista. wordpress.com/2015/10/13/hablando-de-activismomas-alladel-deber/\#more-167. Acceso en: 13 abr. 2020.

HOLZER Boris; SØRENSEN, Mads P. Rethinking subpolitics: beyond the "iron cage" of modern politics? Theory, Culture and Society, London, v. 20, n. 2, p. 79-102, 2003.

HOFFMANN, Bert. Civil society 2.0? How the internet changes state-society relations in authoritarian regimes: the case of Cuba. GIGA Working Papers, n. 156, p. 1-33, 2011. Disponible en: https://www.econstor.eu/bitstream/10419/47847/1/655581456. pdf. Acceso en: 21 mayo 2020. 
IPS - Inter Press Service en Cuba. Del activismo digital a la acción ciudadana 2012-2019. IPS, [Online], 3 feb. 2020. Disponible en: https://www.ipscuba.net/sociedad/2019-del-activismo-digitala-la-accion-ciudadana/. Acceso en: 3 mayo 2020.

IPS - Inter Press Service en Cuba. Red de Mujeres Cubanas Afrodescendientes analiza reforma constitucional. IPS, [Online], 22 ago. 2018. Disponible en: https://www.ipscuba.net/genero/ red-de-mujeres-cubanas-afrodescendientes-analiza-reformaconstitucional/. Acceso en: 12 mayo 2020.

KING, Chester. AfroCubaWeb: unos temas que seguimos. Cuban Studies, Pittsburgh, n. 48, p. 394-402, 2019.

McADAM, Doug; McCARTHY, John; MAYER, Zald. Comparative perspectives on social movements: political opportunities, mobilizing structures, and cultural framings. New York: Cambridge University Press, 1996.

McCANN, Michael. Law and social movements: contemporary perspectives. Annual Review of Law and Social Science, Palo Alto, v. 2, p. 17-38, 2006.

MELUCCI, Alberto. The process of collective identity. In: JOHNSTON, Hant; KLANDERMANS, Bert (ed.). Social movements and culture. 3. ed. Minneapolis: University of Minnesota Press, 2004. p. 41-63.

MESA-LAGO, Carmelo. Cuba en la era de Raúl Castro. Madrid: Colibrí, 2012.

MESA-LAGO, Carmelo. Problemas sociales y económicos en Cuba durante la crisis y la recuperación. Revista de la CEPAL, [Online], n. 86, p. 183-205, ago. 2005. Disponible en: https://www.cepal. org/es/publicaciones/11076-problemas-sociales-economicoscuba-durante-la-crisis-la-recuperacion. Acceso en: 22 oct. 2012. PADRÓN CUETO, Claudia. Más de 8 mil firmas piden ley de protección animal en Cuba. OnCuba News, [Online], 8 mar. 2016. Disponible en: https://oncubanews.com/cuba/mas-de-8mil-firmas-piden-ley-de-proteccion-animal-en-cuba/. Acceso en: 15 mayo 2020. 
PIKARA MAGAZINE. Magín, el grupo feminista cubano que no fue oportuno. Video entrevista a fundadoras de MAGIN. Pikara Magazine, [Online], 8 ago. 2018. Disponible en: https:// www.pikaramagazine.com/2018/08/magin-el-grupo-feministacubano-que-no-fue-oportuno/. Acceso en: 15 feb. 2020.

ROSSI, Federico M. Conceptualizing strategy making in a historical and collective perspective. In: ROSSI, Federico M.; VON BÜLOW, Marisa. Social movement dynamics. New perspectives on theory and research from Latin America. New York: Routledge, 2015. p. 15-42.

RUBIERA, Daysi. Grupo Afrocubanas. Reivindicarse a través del conocimiento. Negra Cubana Tenia que Ser, [Online], 9 oct. 2018. Disponible en: https://negracubanateniaqueser. com/2018/10/09/daysi-rubiera-afrocubanas-es-una-actitudante-la-vida/. Acceso en: 18 abr. 2020.

SÁNCHEZ-DUARTE, José Manuel; FERNÁNDEZ ROMERO, Diana. Subactivismo feminista y repertorios de acción colectiva digital: prácticas ciberfeministas en Twitter. El Profesional de la Información, [Online], v. 26, n. 5, p. 894-902, 2017.

TARROW, Sidney. Power in movement: social movements and contentious politics. New York: Cambridge University Press, 2011.

TILLY, Charles. From mobilization to revolution. AddisonWesley: Reading, 1978.

TORRES SANTANA, Ailyn. El año de la disputa por la Carta Magna. OnCuba News, [Online], 4 feb. 2019. Disponible en: https://oncubanews.com/opinion/columnas/sin-filtro/el-anode-la-disputa-por-la-carta-magna/. Acceso en: 22 mayo 2019.

TORRES SANTANA, Ailyn. Una auditoría de género para la nueva Constitución. OnCuba News, [Online], 24 jul. 2018. Disponible en: https://oncubanews.com/opinion/columnas/sin-filtro/ una-auditoria-genero-la-nueva-constitucion/. Acceso en: 22 mayo 2019. 
VON BÜLOW, Marisa. The survival of leaders and organizations in the digital age: lessons from the Chilean student movement. Mobilization - An International Quaterly, [Online], v. 23, n. 1, p. 45-64, 2018.

VON BÜLOW, Marisa; VILAÇA Luiz; ABELIN, Pedro Henrique. Varieties of digital activist practices: students and mobilization in Chile. Information, Communication \& Society, London, p. 1-20, 2018. DOI: https://doi.org/10.1080/1369118X.2018.1451550. Acceso en: 23 mayo 2020.

ZABALA ARGÜELLES, María del Carmen. Análisis de la dimensión racial en los procesos de reproducción de pobreza. El rol de las políticas sociales para favorecer la equidad social en Cuba. In: ZABAlA ARGÜELlES, María del Carmen (comp.). Pobreza, exclusión social y discriminación étnico-racial en América Latina y el Caribe. Bogotá: Siglo del Hombre Editores; Clacso, 2008. p. 397-422. Disponible en: http://biblioteca.clacso.edu. ar//ar/libros/clacso/crop/zabala/20zaba.pdf. Acceso en: 22 mayo 2014.

ZEMANS, Francis K. Legal mobilization: the neglected role of the law in the political system. Annual Review of Law and Social Science, Palo Alto, v. 2, n. 1, p. 690-703, 1983.

\section{Resumen}

Este artículo analiza la incorporación de diversas acciones (marchas, plantones, acciones performáticas, activismo digital y demandas de legislación) en el repertorio de los colectivos de afrodescendientes, feministas, LGBTI y animalistas en Cuba y su relación con el proceso de aprobación de una nueva Constitución. A partir del análisis tanto de las trayectorias, aprendizajes y experiencias de los movimientos, como del nuevo escenario (donde confluyen el reemplazo constitucional, cambios socioeconómicos y mayor acceso a herramientas digitales) se concluye que estas innovaciones fortalecen su capacidad para articular demandas y posicionarse como interlocutores válidos y legítimos ante el Estado.

Palabras clave: Cuba. Movimientos identitarios. Innovación. Repertorio. Nueva Constitución. 


\section{Abstract}

This article discusses the incorporation of various actions (marches, demonstrations, performative actions, digital activism and demands for legislation) into the repertoire of Afro-descendant, feminist, LGBTI and animalists in Cuba and their relationship with the process of approving a new Constitution. From the analysis of both the trajectories, learning and experiences of movements, as well as the new scenario (where constitutional replacement, socio-economic changes and greater access to digital tools converge) it is concluded that these innovations strengthen their ability to articulate demands and position themselves as valid and legitimate interlocutors before the State

Keywords: Cuba. Identity movements. Innovation. Repertoire. New Constitution.

\section{Resumo}

Este artigo discute a incorporação de diversas ações (marchas, atos públicos, ações performáticas, ativismo digital e demandas por legislação) no repertório de movimentos afrodescendentes, feministas, LGBTI e animalistas em Cuba e sua relação com o processo de aprovação de uma nova Constituição. A partir da análise tanto das trajetórias, aprendizados e experiências dos movimentos, quanto do novo cenário (onde convergem a alteração constitucional, as mudanças socioeconômicas e o maior acesso às ferramentas digitais) conclui-se que essas inovações fortalecem sua capacidade de articular demandas e se posicionarem como interlocutores válidos e legítimos perante o Estado.

Palavras-chave: Cuba. Movimentos identitários. Inovação. Repertório. Nova Constituição.

Recebido em 05 de julho de 2020

Aprovado em 11 de dezembro de 2020 